ALESSANDRO RICARDO CARUSO DA CUNHA

SÍFILIS EM PARTURIENTES DO BRASIL: PREVALÊNCIA E FATORES ASSOCIADOS, 2010-2011 


\section{UNIVERSIDADE DE BRASÍLIA \\ FACULDADE DE CIÊNCIAS DA SAÚDE \\ PROGRAMA DE PÓS-GRADUAÇÃO EM SAÚDE COLETIVA}

ALESSANDRO RICARDO CARUSO DA CUNHA

SÍFILIS EM PARTURIENTES DO BRASIL: PREVALÊNCIA E FATORES ASSOCIADOS, 2010-2011

Dissertação apresentada como requisito parcial para a obtenção do Título de Mestre em Saúde Coletiva pelo Programa de Pós-Graduação em Saúde Coletiva da Universidade de Brasília.

Orientador: Prof. ํㅡ Dr. Edgar Merchan-Hamann

BRASÍLIA 
Ficha catalográfica elaborada automaticamente,

com os dados fornecidos pelo(a) autor(a)

C257e Carumo da Cunha, Alesandro Ricardo

Sifilia en parturientes do Branil : prevalencia e fatoren angociados, 2010-2011 / Alemandro Ricardo Carumo da Cunha; orientador Bdgar Merchan-Hamann. Brasilia, 2015.

$$
82 \mathrm{p} \text {. }
$$

Dienertação (Meatrado - Meatrado Academico en Sabde Coletiva) -- Univeraidade de Braalila, 2015

1. Sorodiagn6atico da Sifilia. 2. Prevalencia. 3. Geatantea. 4. Cuidado Pre-Natal. 5. Brasil. I. Merchan-Hamann, Bdgar, orient. II. Título. 


\title{
SÍFILIS EM PARTURIENTES DO BRASIL: PREVALÊNCIA E FATORES ASSOCIADOS, 2010-2011
}

\begin{abstract}
Dissertação apresentada como requisito parcial para a obtenção do Título de Mestre em Saúde Coletiva pelo Programa de Pós-Graduação em Saúde Coletiva da Faculdade de Ciências da Saúde da Universidade de Brasília.
\end{abstract}

Aprovado em: 06 de maio de 2015

BANCA EXAMINADORA

\begin{tabular}{|c|}
\hline $\begin{array}{c}\text { Dr. }{ }^{\circ} \text { Edgar Merchan-Hamann (presidente) } \\
\text { Universidade de Brasília }\end{array}$ \\
\hline $\begin{array}{l}\text { Dr. - Silvana Pereira Giozza } \\
\text { Ministério da Saúde }\end{array}$ \\
\hline $\begin{array}{l}\text { Dr. }{ }^{\text {a }} \text { Helena Eri Shimizu } \\
\text { Universidade de Brasília }\end{array}$ \\
\hline
\end{tabular}


A Yole - minha avó

A Mirian - minha mãe

A Viviane - minha irmã 


\section{AGRADECIMENTOS}

Ao Professor Edgar Merchan-Hamann, orientador desta dissertação, portanto responsável por muitos dos pontos positivos deste estudo.

Ao Programa de Pós-Graduação em Saúde Coletiva da Universidade de Brasília, pela oportunidade de realização do curso de mestrado. E, aos professores pela oportunidade de aprendizado, e muito especialmente a:

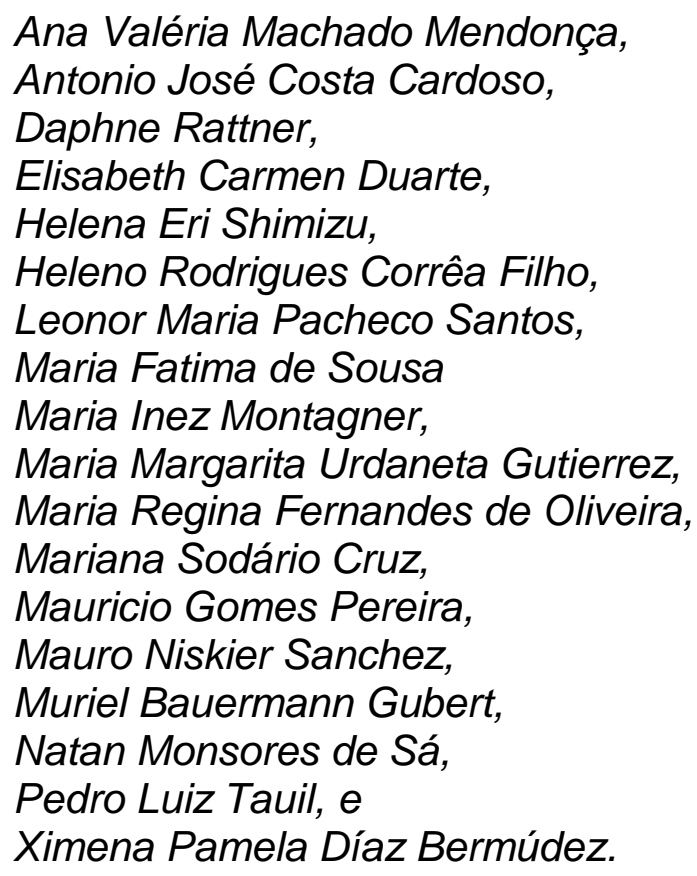

A Fabiana de Carvalho Martins e Ivanaldo Raimundo de Souza Moura, que diligentemente secretariaram os trabalhos do Programa de Pós-Graduação em Saúde Coletiva.

Ao Departamento de Vigilância, Prevenção e Controle das DST, Aids e Hepatites Virais, da Secretaria de Vigilância em Saúde, do Ministério da Saúde, que viabilizou a realização deste trabalho pela cessão da base de dados e pelo apoio para a realização deste mestrado. E, muito especialmente a Coordenação Geral de Informações Estratégicas e a Assessoria de Monitoramento e Avaliação. 
À equipe do Laboratório de Pesquisa em HIV/AIDS da Universidade de Caxias do Sul, pela disponibilidade e amabilidade.

Ao amigo Gerson Fernando Mendes Pereira, pelo inestimável apoio para a realização do mestrado.

Ao Raimundo Nonato Medeiros Costa, pelo espírito iluminado de energia e bondade e, apoio ao longo do período de elaboração deste trabalho.

A Carmen Silvia Bruniera Domingues e Valdir Monteiro Pinto, pela gentileza da discussão sobre muitos aspectos deste trabalho.

Afortunadamente, pude contar com a consultoria do profissional especialista em estatística, Silvano Barbosa de Oliveira, para o emprego do instrumental estatístico que perfaz este estudo; meu muito obrigado.

A Angela Gasperin Martinazzo, que leu o manuscrito e fez comentários valiosos.

Aos amigos da pós-graduação, que me proporcionaram conhecimentos e agradáveis momentos de convivência.

Finalmente, gostaria de expressar meus agradecimentos a todos os que colaboraram, direta ou indiretamente, para a realização deste estudo. 
"[...] talvez não tenhamos conseguido fazer o melhor, mas lutamos para que o melhor fosse feito [...]. Não somos o que deveríamos ser, não somos o que iremos ser. Mas, graças a

Deus, não somos o que éramos"

(Martin Luther King). 


\section{RESUMO}

CUNHA, A. R. C. Sífilis em parturientes do Brasil: prevalência e fatores associados, 2010-2011. Brasília: Universidade de Brasília, Faculdade de Ciências da Saúde; 2015. $82 \mathrm{f}$.

Introdução: apesar da secular descoberta do agente etiológico da sífilis, da existência de métodos de diagnóstico confiáveis, simples e acessíveis e da terapêutica disponível desde 1943, a sífilis persiste como um problema de saúde pública. Objetivo: estimar a prevalência e fatores associados da sífilis em parturientes do Brasil. Método: estudo transversal de base populacional, realizado entre parturientes de 15 a 49 anos de idade, atendidas em maternidades do sistema público de saúde e conveniadas, no período de janeiro de 2010 a dezembro de 2011. Os fatores associados foram computados pela razão de prevalência, estimada pelo modelo de regressão logística. O nível de significância utilizado foi de 5\%. Resultados: foram analisadas informações de 36713 parturientes. A prevalência geral da sífilis foi estimada em 0,89\%; nas regiões Norte, Nordeste, Sudeste, Sul e Centro-Oeste, foi de 1,05\%, 1,14\%, 0,73\%, 0,48\% e 1,20\%, respectivamente. Das parturientes, $98,5 \%$ acessaram o pré-natal, $96,9 \%$ realizaram pelo menos uma consulta e $93,5 \%$ pelo menos um exame de VDRL no curso da gestação; contudo, $53,1 \%$ das parturientes diagnosticadas durante o pré-natal permaneciam infectadas quando da admissão para o parto. As parturientes pretas, amarelas e pardas e as de menor escolaridade apresentam mais risco do que as brancas e de maior escolaridade. Conclusões: de maneira geral, observa-se uma diminuição da prevalência da sífilis no Brasil. Porém, entre as parturientes amarelas, pretas e pardas, assim como as analfabetas, observa-se um aumento na ocorrência da doença, o que reforça a associação desse agravo com as desigualdades sociais. A baixa qualidade da assistência pré-natal parece contribuir ainda mais para agravar a situação nesse contexto de desigualdades, colocando o tratamento como uma grande barreira para o país seguir avançando na redução da prevalência da sífilis no Brasil.

Palavras-chave: Sorodiagnóstico da Sífilis. Prevalência. Gestantes. Cuidado PréNatal. Brasil. 


\section{ABSTRACT}

CUNHA, ARC. Syphilis in pregnant women in Brazil: prevalence and associated factors, 2010-2011. Brasilia: University of Brasilia, Faculty of Health Sciences; 2015. $82 \mathrm{f}$.

Introduction: Despite the secular discovery of the causative agent of syphilis, the existence of reliable methods of diagnosis, simple, affordable and available therapy since 1943, syphilis remains a public health problem. Objective: To estimate the prevalence and the associated factors of syphilis in pregnant women in Brazil. Method: Cross-sectional population-based study conducted among pregnant women from 15-49 years of age, met in maternity hospitals in the public health system and hospitals that have partnership with the public service, from January 2010 to December 2011. The associated factors were computed by the prevalence ratio estimated by logistic regression model. The level of significance was $5 \%$. Results: information from 36,713 pregnant women was analyzed. The overall prevalence of syphilis was estimated at $0.89 \%$; in the North, Northeast, Southeast, South and Midwest, was $1.05 \%, 1.14 \%, 0.73 \%, 0.48 \%$ and $1.20 \%$, respectively. Of the mothers, $98.5 \%$ accessed prenatal, $96.9 \%$ had at least one visit and $93.5 \%$ at least one test of VDRL in the course of pregnancy; however, $53.1 \%$ of pregnant women diagnosed during prenatal remained infected at admission for delivery. Black mothers, yellow and brown and with less education have higher risk than white and level of education. Conclusions: in general, there is a decrease in the prevalence of syphilis in Brazil. However, among the yellow, black and brown women as well as the illiterate, there is an increased occurrence of the disease, which reinforces the association of this condition with social inequalities. The low quality of prenatal care appears to contribute even more to aggravate the situation in this context of inequality, making the treatment as a major barrier to the country move forward in reducing the prevalence of syphilis in Brazil.

Keywords: Syphilis Serodiagnosis. Prevalence. Pregnant Women. Prenatal Care. Brazil. 


\section{LISTA DE FIGURAS}

Figura 1 - Diagrama de fluxo do progresso amostragem de parturientes para o estudo de prevalência. Brasil, 2010-2011 ..........................................................37 


\section{LISTA DE TABELAS}

Tabela 1 - Distribuição das parturientes segundo resultado do teste de sífilis e antecedentes epidemiológicos. Brasil, 2010-2011 .51

Tabela 2 - Distribuição das parturientes segundo resultado do teste de sífilis e características relacionadas ao pré-natal. Brasil, 2010-2011 .52 Tabela 3 - Prevalência segundo características associadas a positividade da sífilis no momento do parto. Brasil, 2010-2011 ..................................................... 53 Tabela 4 - Estimativa do modelo logístico univariado e multivariado das características associadas a positividade da sífilis no momento do parto. Brasil, 2010-2011 .54 


\title{
LISTA DE ABREVIATURAS E SIGLAS
}

\author{
AIDS Síndrome da Imunodeficiência Adquirida \\ CAPES Coordenação de Aperfeiçoamento de Pessoal de Nível Superior \\ CIE Coordenação Geral de Informações Estratégicas \\ CONEP Comissão Nacional de Ética em Pesquisa \\ DATASUS Departamento de Informática do Sistema Único de Saúde \\ DDAHV Departamento de DST, Aids e Hepatites Virais \\ DST Doenças Sexualmente Transmissíveis \\ FS $\quad$ Faculdade de Ciências da Saúde
}

FTA-ABS Fluorescent Treponemal Antibody-Absorption Test; Teste de Absorção do Anticorpo Treponêmico Fluorescente

GARPR Global AIDS Response Progress Reporting; Relatório de Progresso da Resposta Global de AIDS

GM Gabinete do Ministro

HIV Vírus da Imunodeficiência Humana

IBGE Instituto Brasileiro de Geografia e Estatística

LACEN Laboratórios Centrais de Saúde Pública

LPHA Laboratório de Pesquisa em HIV/AIDS

MS Ministério da Saúde do Brasil

OMS Organização Mundial da Saúde

OPAS Organização Pan-Americana de Saúde 
PPGSC Programa de Pós-graduação em Saúde Coletiva

RPR Rapid Plasma Reagin; prova de Reagina Plasmática Rápida

RPSP Revista Panamericana de Salud Pública; Revista Panamericana de Saúde Pública

SC Sífilis Congênita

SINAN Sistema de Informação de Agravos de Notificação

STROBE Strengthening the Reporting of Observational Studies in Epidemiology; Aprimorando a Apresentação de Resultados de Estudos Observacionais em Epidemiologia.

SUS Sistema Único de Saúde

SVS Secretaria de Vigilância em Saúde

T. pallidum Treponema pallidum

TCLE Termo de Consentimento Livre e Esclarecido

TPHA Treponema pallidum Hemagglutination; Treponema pallidum Hemaglutinação

UCS Fundação Universidade de Caxias do Sul

UnB Universidade de Brasília

UNESCO Organização das Nações Unidas para a Educação, a Ciência e a Cultura

UNICEF Fundo das Nações Unidas para a Infância

VDRL Veneral Disease Research Laboratory; Teste do Laboratório de Pesquisa de Doenças Venéreas 


\section{SUMÁRIO}

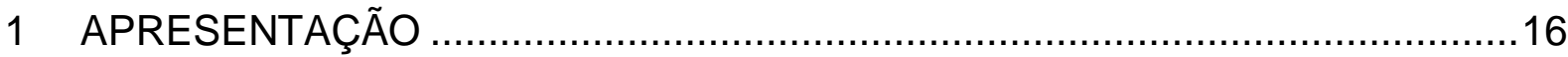

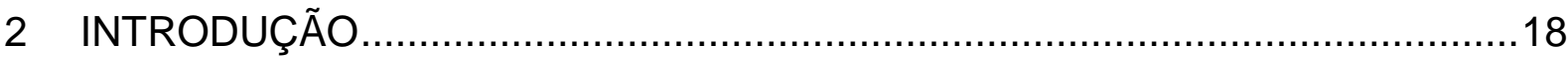

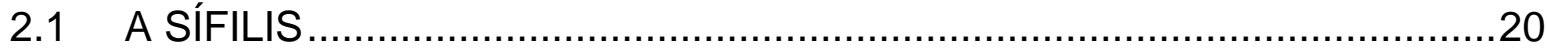

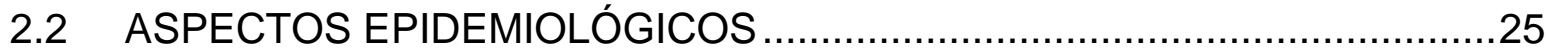

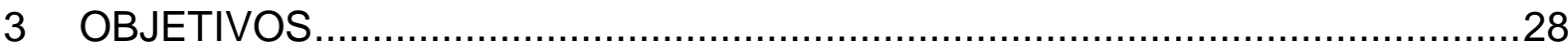

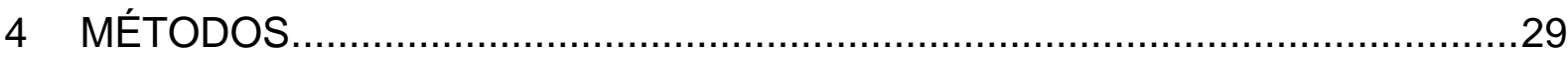

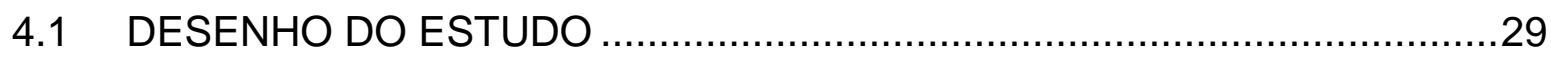

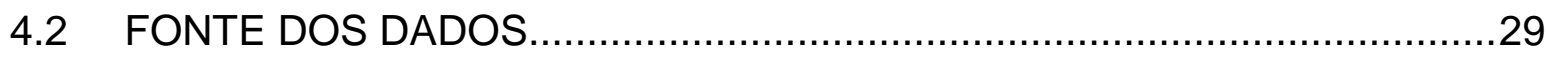

4.2.1 Síntese do projeto original ................................................. 30

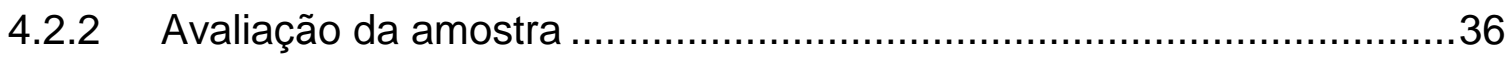

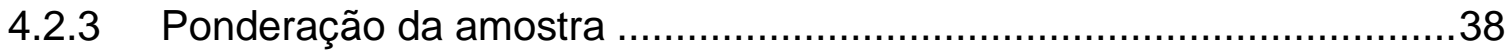

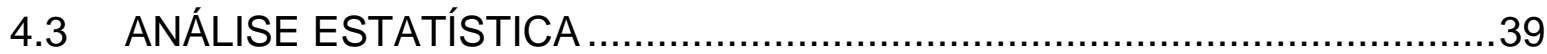

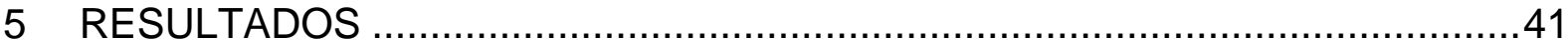

5.1 ARTIGO - SÍFILIS EM PARTURIENTES DO BRASIL: PREVALÊNCIA E

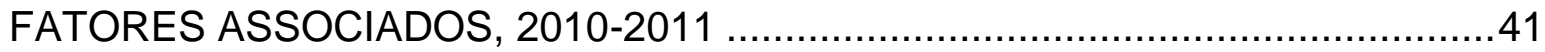

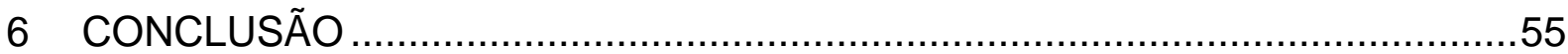

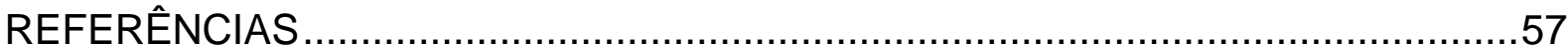

ANEXO A - Termo de Consentimento Livre e Esclarecido (TCLE) .......................67

ANEXO B - Distribuição da amostra selecionada segundo estratos das regiões e

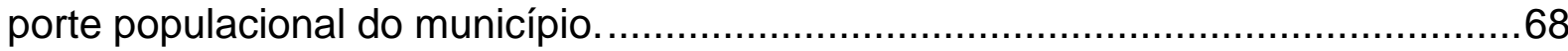

ANEXO C - Questionário de Registro de Dados ............................................. 77

ANEXO D - Parecer do Comitê de Ética em Pesquisa para pesquisa original..........79 


\section{APRESENTAÇÃO}

O ponto de partida para este estudo foi uma proposta da Coordenação Geral de Informações Estratégicas (CIE), do Departamento de DST, Aids e Hepatites Virais (DDAHV), da Secretaria de Vigilância em Saúde (SVS), do Ministério da Saúde do Brasil (MS), no sentido de realizar, durante o biênio 2014-2015, a análise e divulgação de resultados do "Projeto de verificação de prevalência do HIV e sífilis em parturientes, Brasil, 2009", cabendo ao presente autor analisar aspectos da prevalência da sífilis, de forma a responder às necessidades de compreensão científica, com precisão na expressão da teoria e de conceitos fundamentais. Por outro lado, também concorreram novas necessidades de formação pessoal que, seguramente, fazem parte do contexto e apontam para cenários futuros de atuação profissional.

O referido projeto foi financiado pelo MS e pela Organização das Nações Unidas para a Educação, a Ciência e a Cultura (UNESCO), no âmbito do Projeto de Cooperação 914-BRA/1101 para a redução da incidência de Doenças Sexualmente Transmissíveis (DST) e de infecção pelo Vírus da Imunodeficiência Humana (HIV), melhoria da qualidade de vida de pessoas vivendo com HIV e a Síndrome da Imunodeficiência Adquirida (AIDS), por meio do fortalecimento da capacidade de resposta nacional e da promoção da equidade, da sustentabilidade e da universalidade. A sua execução se deu em cooperação técnico-científica entre o DDAHV e a Fundação Universidade de Caxias do Sul (UCS), por meio do Laboratório de Pesquisa em HIV/AIDS (LPHA), das Secretarias Estaduais e Municipais de Saúde, dos Laboratórios Centrais de Saúde Pública (LACEN) e das maternidades do Sistema Único de Saúde (SUS) e conveniadas.

Esta dissertação apresenta, com base em uma amostra probabilística, a força com que o Treponema pallidum ( $T$. pallidum) subsiste na população de parturientes de 15 a 49 anos, atendidas em maternidades do sistema público de saúde e conveniadas, no período de janeiro de 2010 a dezembro de 2011, bem como os potenciais fatores associados à infecção. Também envolve estatísticas descritivas 
da amostra, estimativas de prevalência da sífilis por localidade e o ajuste de um modelo de regressão logística para a obtenção dos fatores associados à infecção no Brasil e em suas regiões.

O manuscrito segue as normas para a redação de teses e dissertações do Programa de Pós-graduação em Saúde Coletiva (PPGSC), da Faculdade de Ciências da Saúde (FS), da Universidade de Brasília (UnB), e seu conteúdo está estruturado em: Introdução, Objetivo, Métodos, Resultados, Discussão e Conclusão. Optou-se por apresentar os Resultados e a Discussão no formato de artigo e submetê-lo à publicação em periódico médico para a divulgação da informação científica aos formuladores e implementadores de políticas de saúde e outras partes interessadas no problema abordado. A construção do artigo foi influenciada pela declaração Strengthening the Reporting of Observational Studies in Epidemiology (STROBE - Aprimorando a Apresentação de Resultados de Estudos Observacionais em Epidemiologia, em português).

O periódico escolhido para a divulgação das evidências foi a Revista Panamericana de Salud Pública (RPSP - Revista Pan-americana de Saúde Pública), considerado seu acesso aberto, seu critério Qualis-Periódicos [B2; 20102012] na Coordenação de Aperfeiçoamento de Pessoal de Nível Superior (CAPES) e sua indexação [PubMed/MEDLINE; Web of Science; Social Sciences Citation Index; Journal Citation Reports/Social Sciences Edition; Current Contents/Social \& Behavioral Sciences; Scopus; SciELO Public Health; LILACS; EMBASE; Global Health; Tropical Diseases Bulletin; Nutrition Abstracts and Reviews, Series A: Human and Experimental; Abstracts on Hygiene and Communicable Diseases; Review of Medical and Veterinary Entomology; Directory of Open Access Journals; Latindex; and Redalyc].

A seguir são descritos alguns aspectos da sífilis, como etiologia, manifestações clínicas, diagnóstico, tratamento e contexto epidemiológico. 


\section{INTRODUÇÃO}

Apesar da descoberta secular do agente etiológico da sífilis, da bem definida história natural da doença (1-5), da existência de métodos de diagnóstico confiáveis, simples e acessíveis - incluindo, mais recentemente, os testes rápidos [point-ofcare] como um avanço importante para a triagem (6-9) - e antibioticoprofilaxia disponível desde 1950 (10-16), com boa relação custo-efetividade em diversos contextos em todo o mundo (17-20), a sífilis continua desafiando os serviços de saúde como uma das principais causas de mortalidade infantil $(21,22)$.

Apesar disso, algumas características biológicas da sífilis mantêm a perspectiva otimista quanto à eliminação da doença. $O T$. pallidum é um patógeno exclusivamente humano, sendo a medida terapêutica eficaz (1-6) e sem resistência antimicrobiana à penicilina clinicamente significativa $(23,24)$, isso tudo combinado às técnicas para triagem sorológica e provas diagnósticas atualmente disponíveis $(10,13)$.

No Brasil, as bases para a prevenção, o diagnóstico e o tratamento da sífilis, em especial, da Sífilis Congênita (SC), estão bem estabelecidas (25-29), assim como seu modelo de vigilância epidemiológica, baseado na notificação compulsória nos serviços de saúde públicos e privados de todo o território nacional, tendo a notificação da SC começado em 1986 (30), a da sífilis em gestantes em 2006 (31) e a da sífilis adquirida a partir de 2011 (32).

A Organização Mundial da Saúde (OMS) e a Organização Pan-Americana de Saúde (OPAS), desde 1995, recomendam a eliminação da SC nas Américas, dada a natureza evitável do agravo (33). Em 2000, a Declaração do Milênio firmou o compromisso global do alcance de oito Objetivos de Desenvolvimento, dentre os quais a Redução da Mortalidade Infantil e a Melhoria da Saúde Materna, demonstrando a necessidade de uma intensa priorização, pelos governos, do acesso e da qualidade dos serviços de saúde materno-infantil, focado na prevenção de mortes infantis, incluindo aquelas devidas à SC (34). 
Nesse sentido, em 2009, a OPAS e o Fundo das Nações Unidas para a Infância (UNICEF) lançaram a "Iniciativa Regional para a Eliminação da Transmissão Materno-Infantil do HIV e da Sífilis na América Latina e no Caribe", estabelecendo como meta a redução da incidência de SC para menos de 0,5 casos por 1.000 nascidos vivos até 2015 (35). No ano seguinte, os estados-membros da OPAS aprovaram o "Plano de Ação para a Eliminação da Transmissão Vertical do HIV e da Sífilis Congênita", lançando uma proposta de indicadores para acompanhar os progressos de alcance das metas de eliminação na Região das Américas (36, 37).

Nesse contexto, o governo brasileiro vem estabelecendo estratégias focadas na redução da transmissão vertical da sífilis, como a do "Projeto de Eliminação da Sífilis Congênita", cuja meta era reduzir a incidência para menos de um caso por 1.000 nascidos vivos, e, em 2007, a do "Plano Nacional para a Redução da Transmissão Vertical da Sífilis e do HIV", com a intenção de reduzir a transmissão vertical de forma escalonada e regionalizada, pactuada entre as três esferas de governo mediante o "Pacto pela Saúde" (38). Nessa trajetória, vale ressaltar que, em 2006, o Brasil lançou o referido Pacto no sentido de estabelecer prioridades para a redução da mortalidade materna e infantil e, entre seus indicadores, estava o da incidência de SC $(39,40)$.

Em 2011, visando assegurar à mulher o direito ao planejamento reprodutivo e à atenção humanizada na gestação, no parto e no puerpério, bem como à criança o direito ao nascimento seguro e ao desenvolvimento saudável, o governo brasileiro lançou a Rede Cegonha, provocando, nessa conjuntura, um aumento significativo da capacidade de triagem para sífilis mediante a incorporação de testes sorológicos de execução rápida na Atenção Básica (34).

Contudo, evidências baseadas em tendências dos casos de sífilis em gestantes e de SC notificados no Brasil indicam que o agravo persiste com um grave problema de saúde pública (41).

No Brasil, a prevalência da sífilis é monitorada por meio de estudos transversais, com o objetivo de estabelecer as tendências espaço-temporais da infecção em determinados grupos populacionais, permitindo, inclusive, aferir a capacidade do sistema de vigilância epidemiológica na detecção de casos. Nesse sentido, monitora-se o grupo populacional das parturientes, considerando ser esse 
grupo detentor de taxa de prevalência de sífilis semelhante à apresentada pela população geral feminina (42). Por meio dos dados de prevalência da sífilis entre parturientes, também é possível estimar os casos de sífilis em gestantes, bem como os de SC. Além disso, outros parâmetros, relacionados a estratégias de controle, podem ser estimados, tais como a fração da população que deve ser efetivamente priorizada e qual estratégia é mais efetiva frente à endemia, entre outras; todos relacionados, direta ou indiretamente, à reprodutibilidade do T. pallidum.

Desse modo, o estudo de prevalência da sífilis em parturientes é fundamental para a administração dos mecanismos de vigilância, prevenção e controle da sífilis no país, subsidiando, com mais clareza, as deliberações sobre as políticas e programas de saúde materno-infantil, especialmente em um país com um sistema de atenção à saúde complexo, apresentando amplas desigualdades internas e atuando em diferentes condições demográficas, econômicas, sociais, culturais e de saúde (43).

\subsection{A SÍFILIS}

A sífilis é uma infecção crônica, causada por uma bactéria denominada Treponema pallidum, do gênero Treponema, da família Treponemataceae (44).

O T. pallidum tem forma espiralada [espiroquetídeo], com oito a 20 voltas, medindo cerca de 5-20 micrômetros $(\mu \mathrm{m})$ de comprimento e apenas 0,1 a 0,2 $\mu \mathrm{m}$ de diâmetro, o que impede que seja visualizado ao microscópio comum, exceto quando em campo escuro ou quando tratado com sais de prata, que o tornam mais espesso. Apresenta flagelos característicos que se iniciam na extremidade distal do germe e move-se por rotação em direção à parte média do próprio corpo (45). Quando visto em uma amostra fresca, o T. pallidum exibe um movimento de rotação com flexão [vai-e-vem], característica suficientemente clara para ser diagnosticado. 
A sífilis é transmitida pela via sexual, sífilis adquirida, e verticalmente pela via transplacentária, sífilis congênita, em qualquer momento da gestação. $O$ contato com as lesões, primárias e secundárias, pelos órgãos genitais é responsável por 95\% dos casos de sífilis. Outras formas de transmissão, mais raras e com menor interesse epidemiológico, são aquelas por via indireta, objetos contaminados e por transfusão sanguínea (46).

Na transmissão sexual, a penetração do $T$. pallidum se dá pelas abrasões decorrentes da relação sexual [solução de continuidade]; em seguida, o treponema atinge o sistema linfático regional e, por disseminação hematogênica, outras partes do corpo. Depois de um período de incubação, a resposta do sistema imunológico resulta em exulceração no ponto de inoculação [lesão primária; cancro duro], enquanto a disseminação sistêmica resulta na produção de complexos imunes circulantes que podem depositar-se em qualquer órgão. A resposta imune mediada por anticorpos não tem capacidade de proteção. A imunidade celular é mais tardia, permitindo ao T. pallidum multiplicar-se e sobreviver por longos períodos.

A história natural da doença mostra uma evolução que alterna períodos de atividade com características clínicas distintas [sífilis primária, secundária e terciária] e períodos de latência [sífilis latente] (44), e sua conduta, habitualmente, é definida sorologicamente e não clinicamente (47).

$\mathrm{Na}$ sífilis primária, a lesão específica é o protossifiloma [cancro duro], que surge no local da inoculação, em média, três semanas após a infecção. Em geral, o cancro é indolor e sem manifestações inflamatórias, e regride espontaneamente em período que varia de quatro a cinco semanas, sem deixar cicatriz. No homem, é mais comum no prepúcio, meato uretral ou, mais raramente, intrauretral. Na mulher, é mais frequente nos pequenos lábios, parede vaginal e colo uterino. As manifestações extragenitais mais comuns são a região da boca, língua e região mamária $(48,49)$.

Na sífilis secundária, após período de latência que pode durar de seis a oito semanas, a doença entra novamente em atividade, acometendo a pele e órgãos internos pela disseminação sistêmica do T. pallidum. O acometimento da pele das regiões palmares e plantares é característico nessa fase e evolui no primeiro e 
segundo ano, espontaneamente, para períodos de latência cada vez maiores (48, 49).

Na sífilis terciária, os pacientes desenvolvem lesões localizadas, envolvendo pele e tecido mucoso, sistema cardiovascular e neural e, em geral, a formação de lesão inflamatória nodular [granulomas] relativamente pequena e ausência quase total de espiroquetas. Nessa fase, podem estar acometidos ainda tecido ósseo, músculos e o fígado $(48,49)$.

No ciclo reprodutivo, a sífilis é responsável por importantes resultados adversos durante a gestação, o parto e o período neonatal, incluindo natimortos e mortes neonatais (50), razão pela qual, no Brasil, recomenda-se a realização de três testes diagnósticos em mulheres grávidas: dois no curso do pré-natal e um quando da admissão para o parto $(25,29)$.

O risco de transmissão da sífilis na gestação depende do estágio da gravidez em que o embrião é exposto e da fase de infecção materna (51). Entre 18 a 22 semanas de gestação, o sistema imunológico fetal não é suficientemente capaz de montar uma resposta imune. Além disso, a infiltração da placenta com redução do fluxo sanguíneo para o feto pode levar a restrição do crescimento que, se grave, muitas vezes resulta em morte fetal $(51,52)$.

Estima-se que, na ausência de tratamento, 25\% das gestações de mulheres com sífilis resultaria em aborto ou em natimorto, $11 \%$ das gestações em morte fetal, $13 \%$ em recém-nascidos prematuros ou de baixo peso, e um adicional de $20 \%$ com sinais clínicos de SC (53).

Em países com sífilis endêmica, a triagem da sífilis no pré-natal combinada ao tratamento adequado com penicilina $G$ benzatina pode reduzir o número de natimortos específicos por causa da sífilis em até $82 \%$, os nascimentos pré-termo em $64 \%$ e a mortalidade neonatal relacionada à sífilis em $80 \%$ (48).

Crianças com SC, nos primeiros dois anos de vida, podem apresentar anemia, hepatoesplenomegalia, icterícia, prurido e pseudoparalisia. Mais tarde, as manifestações da SC podem resultar em problemas de desenvolvimento, neurológicos e musculoesqueléticos e, inclusive, óbito em recém-nascidos e crianças (2). 
O diagnóstico da sífilis deve considerar a fase clínica da doença e, embora existam muitos exames laboratoriais e similares úteis ao diagnóstico, não há um único teste ideal (54).

$\mathrm{Na}$ microscopia de campo escuro, identificam-se treponemas vivos pela morfologia [espiroqueta] e movimentos do organismo [vai-e-vem] em material retirado das lesões; portanto não específico, admitindo-se confusão com treponemas saprófitos. Na impregnação pela prata [nitrato de prata], os treponemas são evidenciados apenas pela morfologia do organismo, logo, de modo igualmente inespecífico. Na imunofluorescência direta, anticorpos marcados são aplicados sobre a amostra em que se deseja revelar o antígeno específico [T. pallidum], com a vantagem de permitir a detecção em exsudatos de lesões e em tecidos frescos ou fixados em formalina (54). Os exames de microscopia para a pesquisa do $T$. pallidum são indicados quando da presença de cancro ou lesões mucocutâneas (55).

Nos métodos utilizados para a detecção direta do $T$. pallidum, as sensibilidades dos testes variam de $73,8 \%$ a $78,8 \%$ na microscopia de campo escuro e de $73 \%$ a $100 \%$ na técnica direta de fluorescência para anticorpo (54).

No organismo, o T. pallidum promove o desenvolvimento de dois tipos de anticorpos: i) as reaginas, anticorpos inespecíficos imunoglobulina $M(\lg M)$ e imunoglobulina $\mathrm{G}(\mathrm{lgG})$, dando origem aos testes não treponêmicos [inespecíficos]; e ii) anticorpos específicos contra o T. pallidum, originando os testes treponêmicos [específicos] (44).

As reações sorológicas não treponêmicas mais comumente usadas são o VDRL (Veneral Disease Research Laboratory) e o RPR (Rapid Plasma Reagin).

O VDRL é capaz de detectar anticorpos inespecíficos [reaginas], presentes no soro, o que permite seu emprego em larga escala como triagem sorológica para a sífilis, uma vez que, à exceção da fase imediata ao contágio, as demais fases da sífilis produzem reaginas. A leitura final da prova diagnóstica é feita ao microscópio. Entretanto, uma vez que outras patologias podem induzir a formação de reaginas, toda e qualquer amostra reagente ao VDRL deve ser submetida à pesquisa de 
anticorpos treponêmicos [específicos], tal como a prova do FTA-Abs (Fluorescent Treponemal Antibody Absorption) ou TPHA (Treponema pallidum Hemagglutination).

O RPR é um teste de floculação para o diagnóstico por meio da pesquisa de anticorpos [reaginas] no soro ou plasma, mediante partículas de carvão que possibilitam a leitura visual dos resultados, evitando, assim, a necessidade de uso de microscópio; é uma forma modificada do clássico VDRL.

As sorologias treponêmicas mais geralmente usadas são o TPHA e o FTAABS.

A sensibilidade do VDRL varia de $71 \%$ a $100 \%$, dependendo da fase da infecção, sendo: 78\% [variação: 74\%-87\%] na sífilis primária; 100\% na fase secundária; 95\% [variação: 88\%-100\%] na latente; e 71\% [variação: 37\%-94\%] na tardia. A alta especificidade é de 98\% [variação: 96\%-99\%] (54). Já o RPR tem uma sensibilidade um pouco maior em comparação com o teste VDRL, especialmente na sífilis primária, de 86\% [variação: 77\%-99\%]; na secundária, 100\%; na latente, 98\% [variação: 95\%-100\%]; e na tardia, 73\%. A especificidade atinge 98\% [variação: 93\%-99\%] (54).

Os testes sorológicos não treponêmicos são úteis para triagem e monitoramento do tratamento, enquanto os treponêmicos são utilizados na confirmação do diagnóstico $(44,55)$. Contudo, a utilização de apenas um tipo de teste sorológico é insuficiente para o diagnóstico; cada tipo de teste tem limitações, incluindo a possibilidade de que resultados falso-positivos em testes não treponêmicos estejam associados a diversas condições clínicas não relacionadas à sífilis, incluindo doenças autoimunes, idade avançada e uso de drogas injetáveis (56); por isso, indivíduos com teste não treponêmico reagente devem ser submetidos a teste treponêmico para confirmação do diagnóstico de sífilis.

A penicilina é a droga de primeira linha para tratamento de todas as fases da sífilis [primária, secundária e terciária], e a análise clínica do caso indicará o melhor esquema terapêutico $(44,48,57,58)$. Em contraste com outros agentes antimicrobianos disponíveis, a eficácia da penicilina para a sífilis permanece estável (16). 
O uso de penicilina em gestantes com sífilis reduz significativamente o risco de SC, morte fetal e parto prematuro. Com base em estudos sobre a incidência da SC, estima-se que a detecção da infecção por sífilis materna no pré-natal e o tratamento com pelo menos 2,4 milhões de unidades de penicilina reduz a incidência de SC em até $97 \%(48,59)$.

\subsection{ASPECTOS EPIDEMIOLÓGICOS}

Segundo dados de incidência da OMS, mais de um milhão de pessoas adquirem uma DST a cada dia; a cada ano, aproximadamente 499 milhões adquirirem DST curáveis, i.e., com etiologia atribuída ao T. pallidum [sífilis], Neisseria gonorrhoeae [gonorreia], Chlamydia trachomatis [clamídia] e Trichomonas vaginalis [tricomoníase] (60).

Tendo por base dois estudos da OMS realizados em 2005 e 2008, com a mesma abordagem metodológica para estimativa de novos casos de DST curáveis [clamídia, gonorreia, sífilis e tricomoníase], em adultos entre 15 a 49 anos de idade, infere-se um acréscimo de aproximadamente $11 \%$ no número de casos, passando de 448,3 milhões, em 2005, para 498,9 milhões de novos casos em 2008, sugerindo que não houve uma melhora na carga global das DST curáveis no período $(60,61)$.

Quanto à sífilis, especificamente, estimativas indicam que aproximadamente 36 milhões de pessoas estejam infectadas no mundo, sendo 12 milhões de novos casos a cada ano (62). Embora a sífilis represente um evento raro em países mais ricos, um leve incremento nas taxas de incidência tem sido observado em vários países europeus e nos EUA nos últimos anos (63). Já a América Latina e o Caribe contribuem com cerca de três milhões de casos de sífilis anualmente (50). Contudo, a maior carga da doença continua a ser registrada na África Subsaariana e na Ásia, onde cerca de 10 milhões de casos ocorrem a cada ano (64). 
Em 2008, segundo estimativas da OMS, 1,4 milhão [1.360.485, variação $1,160,195-1,560,776]$ de gestantes em todo o mundo estavam infectadas com sífilis (65), resultando em cerca de 215.000 natimortos [em > 28 semanas] ou mortes fetais precoces [22 a 28 na semana], 90.000 mortes neonatais, 65.000 casos de prematuridade ou baixo peso ao nascer e 150.000 infecções congênitas (50).

Usando uma modelagem baseada em dados informados por meio do Global AIDS Response Progress Reporting (GARPR) e métodos previamente publicados, a OMS estima que, em 2012, havia cerca de 950.000 gestantes com sífilis, o que acarretaria 370.000 resultados adversos, incluindo 150.000 mortes fetais ou natimortos, 50.000 nascidos prematuros ou de baixo peso ao nascer, 60.000 mortes neonatais e 110000 bebês com infecção congênita (61).

De 2008 a 2012, as infecções de sífilis materna e resultados adversos na gravidez diminuíram em 33\%. Embora a Índia sozinha tenha representado 37\% desse declínio devido a melhorias na qualidade dos dados e esforços de controle de DST, mesmo quando esse país foi excluído da análise, o declínio persistiu em 11\% para infecções de sífilis materna e $10 \%$ para os resultados adversos na gravidez. Esses dados são um sinal promissor de que os esforços para o controle da sífilis em mulheres grávidas e outras populações estão exercendo um impacto na saúde pública (61). Entretanto, a prevalência da sífilis gestacional nos países da América Latina e Caribe destaca-se entre as mais altas do mundo; estima-se que nessa região nasçam entre 164.000 e 344.000 crianças com SC a cada ano (61).

Em 2007, a OMS relatou estimativas globais de SC com base em uma revisão de dados publicados no período de 1997 a 2003, apontando que, anualmente, havia aproximadamente dois milhões [2.036.753] de gestantes com sífilis, das quais 65\% [1.323.889; intervalo: 728.547 para 1.527.565] resultariam em resultados adversos na gravidez (14).

No Brasil, os últimos estudos nacionais de sífilis em parturientes estimaram prevalências gerais de 1,7\% em 2000 (66), 1,6\% em 2004 e 1,1\% em 2006 (67).

Entre 2005 e 2012, foram notificados no Sistema de Informação de Agravos de Notificação (SINAN) 57.700 casos de sífilis em gestantes no país. Em 2011, o número de casos notificados foi de 14.321, dos quais 6.488 [45,3\%] na Região 
Sudeste, 3.359 [23,5\%] na Região Nordeste, 1.687 [11,8\%] na Região Norte, 1.329 [9,3\%] na Região Centro-Oeste, e 1.458 [10,2\%] na Região Sul. Com relação à taxa de detecção de sífilis em gestantes, em 2011, foi calculada em 5,0 casos por 1.000 nascidos vivos. De modo geral, as maiores proporções de gestantes com sífilis encontram-se na faixa etária entre 20 e 29 anos [52,4\%] e em duas faixas de escolaridade distintas: da $5^{\underline{a}}$ à $8^{\underline{a}}$ série incompleta $\left[22,1 \%\right.$ e da $1^{\underline{a}}$ a $4^{\underline{a}}$ série incompleta [10,8\%]. Quanto à raça e cor, predominam a parda [46,5\%] e a branca $[28,7 \%](68)$.

Com relação à SC, entre 1998 e 2012, foram notificados no SINAN 80.041 casos de SC em menores de um ano de idade; a Região Sudeste registrou 36.770 [45,9\%] desses casos; o Nordeste, 25.133 [31,4\%]; o Norte, 6.971 [8,7\%]; o Sul, 6.143 [7,7\%]; e o Centro-Oeste, 5.024 [6,3\%]. Em 2011, foram notificados 9.374 novos casos de SC em menores de um ano de idade, dos quais 4.083 [43,6\%] na Região Sudeste, 3.188 [34,0\%] na Região Nordeste, 908 [9,7\%] na Região Sul, 801 [8,5\%] na Região Norte, e 394 [4,2\%] na Região Centro-Oeste. Com relação à detecção de SC no Brasil, em 2011, foi calculada uma taxa de 3,3 casos por 1.000 nascidos vivos, sendo que as Regiões Nordeste e Sudeste apresentaram as maiores taxas para esse ano, sendo 3,8 e 3,6, respectivamente (68).

Diante desse quadro epidemiológico, este estudo traz uma dimensão da magnitude da sífilis no Brasil, provendo informações que possam vir a contribuir para o aprimoramento de programas de controle da sífilis, e, em especial, de prevenção da SC. 


\section{OBJETIVOS}

O objetivo deste estudo é estimar a prevalência da sífilis em parturientes de 15 a 49 anos de idade atendidas em maternidades do SUS e conveniadas, no Brasil e regiões, no período de janeiro de 2010 a dezembro de 2011, assim como investigar os potenciais fatores associados à infecção. 


\section{MÉTODOS}

\subsection{DESENHO DO ESTUDO}

Utilizou-se um desenho de estudo transversal, descritivo e analítico, de base institucional, atrelado a territórios, entre parturientes de 15 a 49 anos de idade atendidas em maternidades do sistema público de saúde e conveniadas, com exceção das mulheres internadas para curetagem pós-abortamento, no período de janeiro de 2010 a dezembro de 2011. O estudo é descritivo, pois analisa atributos da população, os quais, em conjunto, definem o quadro em estudo, em época e locais estabelecidos; e analítico, por explicar diferentes características da doença observada.

\subsection{FONTE DOS DADOS}

Os dados utilizados neste estudo provêm do "Projeto de verificação de prevalência do HIV e sífilis em parturientes, Brasil, 2009”.

Aspectos metodológicos do projeto original, relevantes para o presente estudo, serão apresentados a seguir para que se possa acompanhar o que foi planejado e executado, subsidiando a avaliação dos resultados encontrados neste estudo e as conclusões que foram extraídas. 


\subsubsection{Síntese do projeto original}

O "Projeto de Verificação de Prevalência do HIV e Sífilis em Parturientes, Brasil, 2009", previu estimar a prevalência dos dois agravos entre parturientes lançando mão de dois procedimentos: entrevistas e exames diretos, em consonância com os objetivos pré-estabelecidos; testes laboratoriais para determinação das infecções [sífilis e HIV] e informações obtidas mediante entrevistas com as parturientes e de coleta de informações do cartão pré-natal, prontuários e laudos de diagnósticos, utilizando um questionário estruturado por ocasião da admissão das parturientes para o parto. $O$ trabalho de campo foi integrado à rotina dos serviços das maternidades selecionadas no processo de amostragem, de forma a não comprometer a assistência prestada.

\subsubsection{Desenho do estudo}

Estudo epidemiológico transversal, entre gestantes atendidas pelo sistema público de saúde [maternidades públicas e conveniadas], durante o período de janeiro de 2010 a dezembro de 2011. 


\subsubsection{Participantes}

Foram consideradas elegíveis para o estudo as parturientes de 15 a 49 anos de idade atendidas em maternidades do sistema público de saúde ou conveniadas, com exceção das mulheres internadas para curetagem pós-abortamento, e que consentiram em participar como voluntárias, mediante assinatura de Termo de

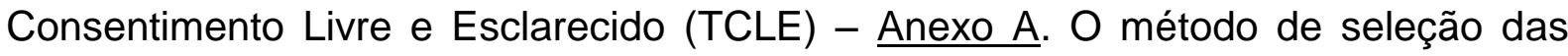
participantes foi aleatório quando da admissão para o parto.

\subsubsection{Tamanho do estudo}

O desenho amostral foi delineado de modo a permitir a inferência, em termos probabilísticos, da proporção de gestantes infectadas pelo HIV no Brasil, considerando, inclusive, a divisão regional do país [Norte, Nordeste, Sudeste, Sul e Centro-Oeste].

Para o cálculo do tamanho da amostra, considerou-se a estimativa da proporção de gestantes infectadas pelo HIV no Brasil referente ao ano de 2006, calculada em $0,41 \%$ (69), dentro de um intervalo de confiança de 95\%, com erro bicaudal de 0,15\% [39.819] e efeito de desenho de 1,1 [10\%], resultando em uma amostra estimada de 43.800 parturientes.

A amostragem foi selecionada em dois estágios: i) no primeiro, foram selecionadas 221 maternidades, entre aquelas que realizaram mais de 500 partos no ano de 2007 - critério estabelecido para que o trabalho de campo não excedesse o período de seis meses a dois anos -, estratificadas pelas cinco regiões do país [Norte, Nordeste, Sul, Sudeste e Centro-oeste] e segundo porte populacional [até 50.000; 50.001 a 400.000; ou 400.001 e mais habitantes] do município de 
localização das maternidades; ii) no segundo estágio, para cada um dos estratos, foram selecionadas 15 maternidades com probabilidade proporcional ao tamanho, considerando o número de partos realizados em 2007 - Anexo B. Em cada maternidade, foram selecionadas, aleatoriamente, 200 parturientes quando do momento da admissão para o parto. Perdas por recusa foram repostas pela seleção de novas parturientes.

\subsubsection{Procedimentos}

Foram realizadas entrevistas utilizando, para a coleta de informações, um questionário estruturado composto de questões fechadas, desenvolvido especificamente para o projeto - Anexo $\mathrm{C}$. No questionário, consideraram-se medidas indiretas, provenientes do testemunho prestado pelas parturientes e, em grande parte, medidas diretas, fornecidas pela coleta de dados do cartão de prénatal e prontuário das parturientes, quando disponíveis. $O$ instrumento considerou características sociodemográficas e de cuidado pré-natal, incluindo a realização de exames diagnósticos, e informações sobre o parto; as variáveis estudadas foram:

i) Sociodemográficas: idade, nível de instrução, raça/cor e município de residência;

ii) Do pré-natal: possuir o cartão de pré-natal, número de consultas, trimestre de início das consultas, teste anti-HIV, teste de VDRL, relato de teste de hepatites e vacinação; e

iii) Do parto: data e situação do recém-nascido.

Para o diagnóstico da sífilis, foram realizadas:

i) punção digital para execução de teste rápido treponêmico, da $S D$ Bioline Syphilis 3.0, Standard Diagnostics, Yongin, Korea, como triagem, em todas as parturientes quando da admissão para o parto, mesmo quando do registro de 
realização do teste durante o pré-natal, seguindo as recomendações do MS (25). Os testes foram realizados em todas as maternidades, tendo-se adotado as instruções de execução do fabricante do kit diagnóstico.

Nos casos em que amostra foi reagente para sífilis, ou a parturiente não possuía resultados de VDRL realizados durante o pré-natal, devido: a) não ter realizado o pré-natal; ou b) não ter trazido consigo o cartão de pré-natal ou laudo de VDRL; ou c) ter trazido o cartão de pré-natal sem o resultado de VDRL, procedeu-se a:

ii) coleta de amostra sanguínea por punção venosa para realização de avaliação patológica. As amostras coletadas foram centrifugadas em laboratórios locais e o soro mantido congelado para preservação até o transporte, por empresa especializada em translado de amostras biológicas, ao LPHA da UCS, onde foram submetidas aos procedimentos de testagem sorológica para pesquisa do T. pallidum por meio do teste não treponêmico quantitativo VDRL, da Laborclin, Paraná, Brasil, e os testes treponêmicos FTA-Abs e TPHA, da WAMA Diagnostica, São Paulo, Brasil e Omega Diagnostics LTD., Scotland, United Kingdom, respectivamente.

O fluxograma utilizado para o diagnóstico laboratorial da sífilis seguiu as recomendações do MS descritas na Portaria № 3.242 do Gabinete do Ministro (GM) do MS, de 30 de dezembro de 2011 (28).

\subsubsection{Equipe de campo}

Após a seleção probabilística das maternidades, foram identificados 26 pesquisadores na área de saúde pública para coordenar, localmente, a execução do projeto. Em um segundo momento, 438 profissionais de saúde [biomédicos, enfermeiros, farmacêuticos, médicos, entre outros] pertencentes às 219 maternidades, foram indicados para compor as equipes de pesquisadores de campo. 
Todos os profissionais envolvidos no projeto, sem exceção, foram devidamente treinados para a correta execução do protocolo do projeto. Ademais, um manual foi disponibilizado aos pesquisadores, detalhando todos os procedimentos envolvidos na execução do projeto, desde a logística de insumos à devolução dos laudos sorológicos.

\subsubsection{Recrutamento}

Os profissionais abordaram as parturientes, conferindo o enquadramento aos critérios de elegibilidade do projeto. As elegíveis, tendo concordado em participar do estudo e assinado o TCLE, seguiram com o preenchimento do questionário para obtenção das informações e, em seguida, realizaram os procedimentos para coleta de amostras biológicas [sangue total] visando a execução dos testes rápidos e coleta de alíquota para envio ao LPHA da UCS, visando a realização dos testes confirmatórios.

As parturientes receberam um número, inequívoco, como sendo sua identificação no projeto. Os números de identificação foram atribuídos em ordem sequencial, iniciando em 001, para cada uma das maternidades. Todas as amostras biológicas e formulários contiveram o número de identificação das parturientes, garantindo a rastreabilidade e resguardada a confidencialidade. A exceção foi o TCLE, do qual constaram o número de identificação, o nome e a assinatura das parturientes, pelos atributos inerentes. 


\subsubsection{Banco de dados}

Foi desenvolvido, por profissionais da área de informática da UCS, sob a orientação e colaboração do DDAHV, um sistema informatizado para o gerenciamento do projeto. Além de permitir o monitoramento e a rastreabilidade das informações, o sistema serviu de plataforma para o acesso remoto, via Internet, aos resultados das sorologias.

Para compor o banco de dados do projeto, optou-se por substituir a transcrição manual das informações contidas nos questionários por um processo automatizado realizado com o software Cardiff TeleForm ${ }^{\circledR}$, da Digital Vision, Illinois, EUA, que extraiu as informações registradas nos questionários e as converteu em informações digitais.

Todo o processo automatizado de captura dos dados [extração e exportação] foi rotineiramente checado por um profissional capacitado, com o objetivo de monitorar a qualidade das informações.

\subsubsection{Devolução de resultados laboratoriais}

Os resultados dos testes rápidos foram informados à equipe médica logo após a sua execução. Os laudos das sorologias foram disponibilizados para cada maternidade participante, a posteriori, via Internet. 


\subsubsection{Aspectos éticos}

O protocolo do projeto original atendeu às diretrizes e normas regulamentadoras de pesquisa envolvendo seres humanos descritas na Resolução do Conselho Nacional de Saúde $N^{\circ}$ 196, de 10 de outubro de 1996 [vigente à época], conforme o Parecer $\mathrm{N}^{\circ}$ 709, de 08 de outubro de 2009, emitido pela Comissão Nacional de Ética em Pesquisa (CONEP) do MS - Anexo D.

\subsubsection{Avaliação da amostra}

Da amostra de parturientes estimadas [43.800], o projeto atingiu um total de 38.393 parturientes recrutadas, no período de janeiro de 2010 a dezembro de 2011; destas, 1.379 recusaram participação, reduzindo o universo do estudo para 37.014 parturientes.

A primeira análise das informações coube ao LPHA da UCS, que conferiu a identificação inequívoca dos questionários e das amostras biológicas, bem como a qualidade do material biológico [quantidade, integridade e conservação]; nessa etapa, reduziu-se o universo da amostra, passando de 37.014 para 36.713 parturientes - Figura 1. 


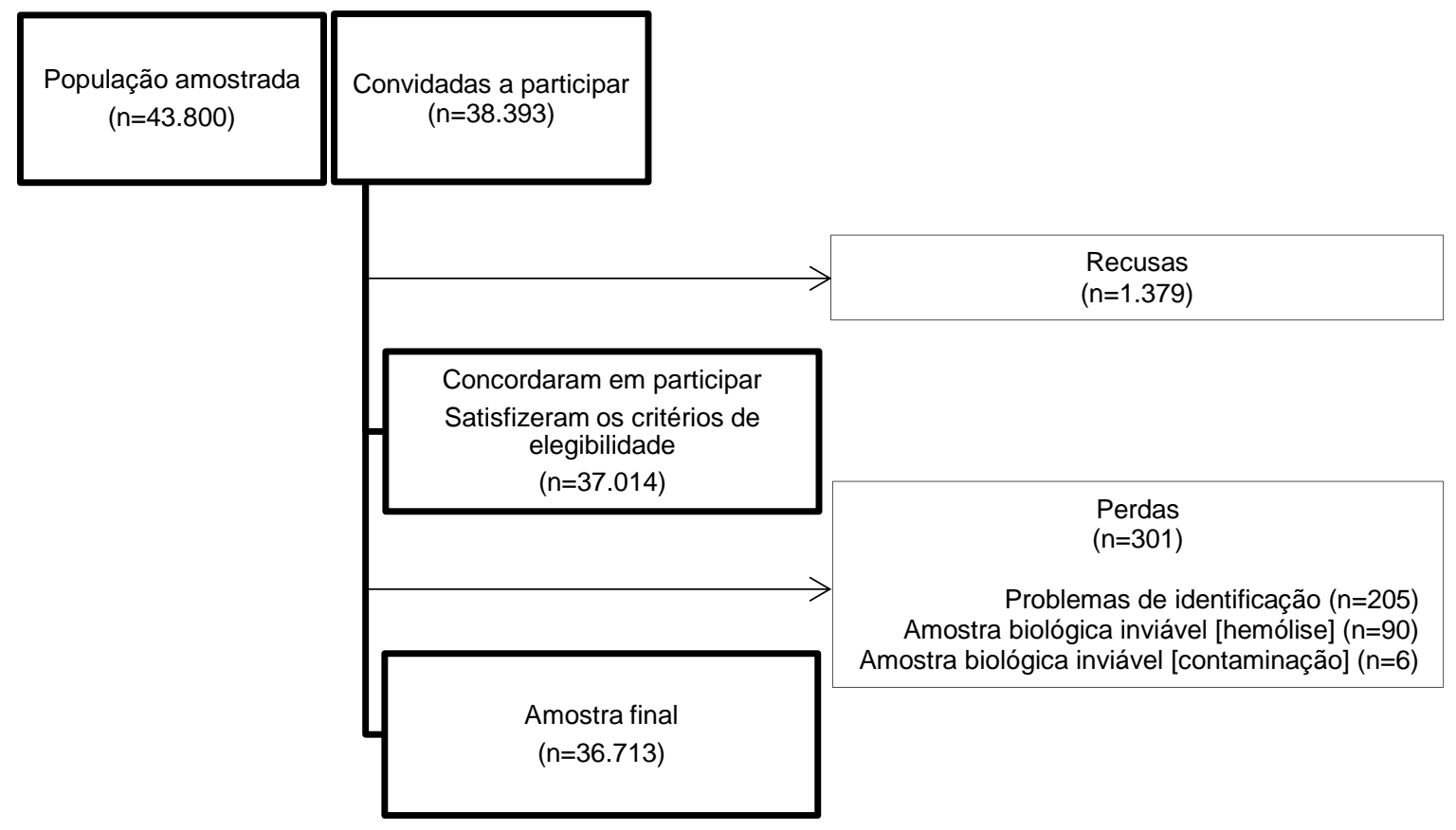

Figura 1 - Diagrama de fluxo do progresso amostragem de parturientes para o estudo de prevalência. Brasil, 2010-2011

Previamente à análise da amostra final, realizou-se a avaliação crítica do banco de dados, com o emprego de técnicas exploratórias de dados, para verificar os padrões de distribuição e tendências das variáveis e analisar a consistência das informações. Nessa etapa, foram resgatados questionários digitalizados e corrigidos, quando possível, os registros de variáveis inconsistentes.

Foram identificadas inconsistências nas seguintes variáveis: Número de Identificação da Parturiente; Data da coleta; Data de nascimento; Data da primeira consulta; Data da realização do Teste 1 de anti-HIV; Data da realização do Teste 2 de anti-HIV; Data da realização do Teste 1 de VDRL; Data da realização do Teste 2 de VDRL; Data do Parto; Título do VDRL no pré-natal; Título do VDRL no Cartão Pré-natal; Fez o pré-natal; Número de consultas de pré-natal; Data da primeira consulta; Realizou o Teste 1 de anti-HIV; Realizou o Teste 2 de anti-HIV; Realizou o Teste 1 de VDRL; Realizou o Teste 2 de VDRL; Realizou teste para diagnóstico de hepatites; Resultado do Teste Rápido de HIV. 


\subsubsection{Ponderação da amostra}

A taxa de prevalência foi estimada considerando a divisão regional do Brasil e o grau de escolaridade das parturientes, segundo Cochran, em 1963, apud Szwarcwald CL e Souza-Júnior, PRB (70). Em cada estrato [h], a taxa de prevalência $[p h]$ e a sua variância $[v h]$ foram estimadas por:

$$
\begin{gathered}
p_{h}=\frac{\sum a_{i h}}{\sum m_{h}} \\
v_{h}=\frac{\sum a_{h}^{2}-2 \mathrm{p}_{h} \sum a_{h} m_{h}+p^{2} \sum m_{h}^{2}}{\mathrm{n}_{h}\left(n_{h}-1\right) m_{h}^{2}}
\end{gathered}
$$

onde $a_{i h}$ é o número de casos positivos no estabelecimento $i$ do estrato $h$ $(h=1, \ldots, 15), m_{h}$ o número de gestantes selecionadas no estabelecimento $i$ do estrato $h, n_{h}$ o número de hospitais selecionados do estrato $h$, e $m_{h}$ o número médio de gestantes em cada estabelecimento de saúde na amostra.

As estimativas totais da taxa de prevalência $p$ e respectiva variância $v$ foram estabelecidas por:

$$
\begin{gathered}
p=\sum_{h} w_{h} p_{h} \\
v=\sum_{h} w_{h}^{2} w v_{h}
\end{gathered}
$$

onde $w_{h}$ representa o peso de cada estrato $h(h=1, \ldots, 15)$. 


\subsection{ANÁLISE ESTATÍSTICA}

A análise estatística cumpriu a seguinte estratégia: i) a geração de estatísticas descritivas da amostra; ii) a obtenção de estimativas de prevalência da sífilis para o Brasil e suas divisões regionais; e iii) o ajuste de um modelo de regressão logística para a obtenção dos fatores associados à infecção pelo $T$. pallidum na população de parturientes estudadas.

A variável dependente a ser explicada neste estudo é o sorodiagnóstico da sífilis. Trata-se de uma variável dicotômica, categorizada em positivo [reagente] e negativo [não reagente]. As variáveis epidemiológicas consideradas foram: i) região de residência [Norte, Nordeste, Sudeste, Sul e Centro-Oeste]; ii) faixa etária [15 a 24 e 25 a 49 anos]; iii) raça e cor [branca, preta, amarela, parda e indígena]; iv) escolaridade [analfabeta, $1^{\text {a }}$ a $4^{\underline{a}}$ série, $5^{\text {a }}$ a $8^{\underline{a}}$ série, segundo grau ou superior incompleto e completo]; v) realização do pré-natal; vi) número de consultas [de uma a cinco, seis ou mais consultas]; vii) possuir o cartão de pré-natal; viii) trimestre de início do pré-natal; ix) realização de VDRL; e x) resultado de VDRL.

As estimativas da prevalência da sífilis foram calculadas para cada grupo utilizando proporções, em que o numerador corresponde ao número de parturientes positivas para sífilis com determinada característica, e o denominador, o total de parturientes com a mesma característica, considerando intervalos de confiança para as proporções a um nível de confiança de $95 \%$; o intervalo de confiança garante que o parâmetro verdadeiro estará presente em pelo menos $95 \%$ das replicações do processo de obtenção dos dados.

As proporções segundo as variáveis analisadas foram comparadas utilizando o teste qui-quadrado $\left[\chi^{2}\right]$, considerando o nível de significância de $5 \%$.

Com o objetivo de identificar potenciais fatores associados ao desfecho de interesse, utilizou-se, para medir a magnitude da associação, a razão de prevalências (71-74), estimada pelo modelo de regressão logística, com seu respectivo intervalo de confiança de $95 \%$. 
$\mathrm{Na}$ análise univariada se investigou, isoladamente, a relação entre as variáveis independentes e a variável dependente. Por sua vez, na análise multivariada se avaliou, simultaneamente, o efeito exercido pelas variáveis selecionadas sobre o desfecho. O modelo final foi definido pelo método stepwise [passo a passo] de seleção das variáveis que mais influenciaram o conjunto de saída do modelo, diminuindo assim o número de variáveis a compor a equação de regressão; considerou-se uma probabilidade de 10\% para entrada das variáveis e $20 \%$ como probabilidade de saída da variável do modelo. Tendo em vista que, em geral, existem associações entre as variáveis independentes, a influência de cada variável foi controlada pelo efeito das demais.

Nas tabelas não serão apresentados valores individualizados das variáveis em estudo, mas intervalos de valores, agrupados em classes, pois tabelas contendo dados individualizados ficariam muito extensas, acrescentando pouca informação em relação à que pode ser obtida com a observação dos dados brutos, não sintetizados. Para o agrupamento em classes, por não haver uma regra fixa para determinação da quantidade e do tamanho dos intervalos, utilizaram-se os padrões aplicados pelo Departamento de Informática do Sistema Único de Saúde (DATASUS) e pelo Instituto Brasileiro de Geografia e Estatística (IBGE).

Para a mineração dos dados, utilizou-se o software estatístico $\mathrm{R}^{\odot}$, da $R$ Foundation for Statistical Computing, Vienna, Austria, versão 3.0.1, atribuindo-se para todas as análises ponderações em conformidade com o plano de amostragem utilizado; a descrição pormenorizada da metodologia já foi publicada (70). 


\title{
5 RESULTADOS
}

\subsection{ARTIGO - SÍFILIS EM PARTURIENTES DO BRASIL: PREVALÊNCIA E FATORES ASSOCIADOS, 2010-2011}

\author{
Alessandro Ricardo Caruso da Cunha',2, Edgar Merchán-Hamann' \\ 'Universidade de Brasília (UnB), Brasília, Brasil \\ 2 Departamento de Vigilância, Prevenção e Controle das DST, Aids e Hepatites Virais, Secretaria de \\ Vigilância em Saúde, Ministério da Saúde, Brasília, Brasil
}

\section{Introdução}

Apesar da secular descoberta do agente etiológico da sífilis (5), da existência de métodos de diagnóstico confiáveis (54), simples e acessíveis - incluindo, mais recentemente, os testes rápidos como um avanço importante para o aumento da cobertura de detecção $(75,76)$ - e da terapêutica disponível desde $1943(16,24)$, com boa relação custo-efetividade em diversos contextos $(19,48)$, a sífilis persiste como um problema de saúde pública, sendo uma das principais causas de mortalidade infantil $(22,61)$.

Segundo dados da Organização Mundial de Saúde, em 2005, aproximadamente 36 milhões de adultos eram portadores de sífilis no mundo, sendo 11 milhões de casos incidentes (62). Em 2008, a estimativa de mulheres grávidas com sífilis foi de 1,4 milhões, resultando em cerca de 290 mil natimortos ou mortes fetais precoces, 122 mil mortes neonatais, 82 mil casos de prematuridade ou baixo peso ao nascer e 218 mil infecções congênitas (61).

No Brasil, as bases para prevenção, diagnóstico e tratamento da sífilis estão bem estabelecidas, assim como seu modelo de vigilância epidemiológica baseado na notificação compulsória nos serviços de saúde públicos e privados de todo o território nacional. A notificação da sífilis congênita começou em 1986, a da sífilis em 
gestantes em 2006 e a da sífilis adquirida em 2011. Evidências baseadas em tendências dos casos de sífilis em gestantes e de sífilis congênita notificados no país indicam que o agravo persiste, desafiando os serviços de saúde. Em 2011, a taxa de detecção da sífilis em gestantes foi calculada em 5,0 casos por 1000 nascidos vivos; com relação à sífilis congênita, a taxa de incidência, em 2011, foi de 3,3 casos por 1000 nascidos vivos (68).

Contudo, a prevalência da sífilis é monitorada no país por meio de estudos transversais em determinados grupos populacionais; o grupo de parturientes é monitorado por apresentar a taxa de prevalência semelhante à da população geral feminina. As últimas estimativas nacionais da sífilis em parturientes variaram de $1,1 \%$ a $1,7 \%$ entre 2000 e $2006(66,77)$.

Desse modo, o estudo de prevalência da sífilis em parturientes é fundamental para a gestão dos mecanismos de vigilância, prevenção e controle, subsidiando, com mais clareza, a tomada de decisão, sobretudo em um país com um sistema de atenção à saúde complexo, apresentando amplas desigualdades internas e atuando em diferentes condições demográficas, econômicas, sociais, culturais e de saúde (43).

O objetivo deste trabalho é fornecer estimativas da prevalência da sífilis em parturientes do Brasil e alguns dos fatores associados à infecção. Foram examinados, de uma amostra complexa referente às cincos regiões do país, cenários variados da prevalência entre parturientes, a fim de retratar resultados para possíveis repercussões na avaliação e no planejamento das políticas públicas desenvolvidas na área da saúde materno-infantil no país.

\section{Material e métodos}

Utilizou-se um desenho de estudo transversal, analítico, de base institucional atrelada a territórios, conduzido entre parturientes de 15 a 49 anos de idade, atendidas em maternidades do sistema público de saúde e conveniadas, com 
exceção das mulheres internadas para curetagem pós-abortamento, no período de janeiro de 2010 a dezembro de 2011.

Para a determinação do tamanho da amostra, utilizou-se a estimativa da proporção de gestantes infectadas pelo HIV no Brasil no ano de 2006, avaliada em 0,41\%, com o nível de confiança de $95 \%$, erro bicaudal de $0,15 \%$, efeito de desenho de 1,1 e perda de 10\%, chegando-se ao tamanho amostral esperado de 43800 parturientes. A amostragem foi estabelecida por conglomerados, tendo sido obtida em dois estágios: i) no primeiro, foram selecionadas 219 maternidades do sistema público de saúde e conveniadas, segundo o porte populacional do município [ $\leq 50$ 000; 50001 a 400 000; 400001 e mais habitantes], e ii) no segundo, as parturientes de 15 a 49 anos de idade, sendo 200 parturientes para cada um dos sítios, elegidas de forma aleatória quando do momento da admissão para o parto.

O modelo de investigação da frequência da sífilis contemplou: i) triagem com teste rápido treponêmico [SD Bioline Syphilis 3.0, Standard Diagnostics, Yongin, Korea] com amostra de punção digital; e ii) coleta de amostra sanguínea para confirmação diagnóstica por meio do ensaio não treponêmico, Venereal Disease Research Laboratory [(VDRL) Laborclin, Paraná, Brasil] e dos ensaios treponêmicos Fluorescent Treponemal Antibody Absorption [(FTA-Abs) WAMA Diagnostica, São Paulo, Brasil] ou do Treponema pallidum haemagglutination [(TPHA) Omega Diagnostics LTD., Scotland, United Kingdom], nos casos em que o teste treponêmico foi reagente ou a parturiente não possuía resultados do teste não treponêmico VDRL realizado durante o pré-natal, devido às seguintes razões: não ter realizado o prénatal; ou não ter trazido consigo o cartão de registro de consultas do pré-natal ou laudo de VDRL; ou ter trazido o cartão de pré-natal sem o resultado de VDRL. As amostras de sangue em análise tiveram o soro separado para o processamento no Laboratório de Pesquisa em HIV/AIDS da Fundação Universidade de Caxias do Sul, onde foram realizados os testes sorológicos. A infecção por sífilis foi definida como resultado reagente do teste não treponêmico com qualquer titulação, e treponêmico com reação positiva.

As informações sociodemográficas, clínicas e institucionais foram coletadas por questionário com variáveis observadas indiretamente, obtidas por meio do testemunho prestado pelas parturientes, e variáveis observadas diretamente, obtidas 
por meio do cartão pré-natal e de registros médicos. A digitalização dos dados se deu por processamento eletrônico, realizado com o software Cardiff TeleForm ${ }^{\circledR}$ [Digital Vision, Illinois, EUA]. Todas as informações foram revisadas por um profissional capacitado, com o objetivo de monitorar a qualidade dos dados.

A equipe de campo, constituída por profissionais da saúde vinculados às maternidades e secretarias estaduais e municipais de saúde, foi capacitada para a execução do protocolo de pesquisa, a compreensão dos riscos envolvidos nos procedimentos e a aplicação do Termo de Consentimento Livre e Esclarecido.

As variáveis epidemiológicas pesquisadas foram: i) região de residência; ii) faixa etária; iii) raça e cor; iv) escolaridade; v) realização do pré-natal; vi) número de consultas; vii) possuir o cartão de pré-natal; viii) trimestre de início do pré-natal; ix) teste VDRL realizado no pré-natal; e x) resultado de VDRL no pré-natal.

Inicialmente, foram calculadas, sobre o total de casos, as proporções referentes aos atributos coletados e procedeu-se ao teste qui-quadrado $\left[\chi^{2}\right]$ para verificar a hipótese de associação entre os antecedentes epidemiológicos e dos serviços e o sorodiagnóstico da sífilis. Posteriormente, foi calculada a prevalência da sífilis sobre o total de parturientes, com seus respectivos intervalos de confiança de 95\%. Os fatores associados foram computados pela razão de prevalência, estimada pelo modelo de regressão logística, com seu respectivo intervalo de confiança. $O$ nível de significância utilizado neste estudo foi de $5 \%$. Todas as análises foram realizadas com o software estatístico $R^{\odot}[R$ Foundation for Statistical Computing, Vienna, Austria], versão 3.0.1, atribuindo-se, para todas as análises, ponderações em conformidade com o plano de amostragem utilizado; a descrição pormenorizada da metodologia já foi publicada (70).

O protocolo do estudo foi aprovado pela Comissão Nacional de Ética em Pesquisa, conforme o Parecer $N^{\circ}$ 709, de 08 de outubro de 2009, e o Termo de Consentimento Livre e Esclarecido foi obtido por escrito a partir da concordância, pelas parturientes, em participar do estudo.

O presente estudo foi financiado pelo Departamento de Vigilância, Prevenção e Controle das DST, Aids e Hepatites Virais, da Secretaria de Vigilância em Saúde 
do Ministério da Saúde do Brasil, e pela Organização das Nações Unidas para a Educação, a Ciência e a Cultura, no âmbito do Projeto 914-BRA/1 101.

\section{Resultados}

Neste estudo, foram analisadas informações de um total de 36713 parturientes, distribuídas pelas cinco regiões do país, sendo 10,6\% na Norte, 29,3\% na Nordeste, $39,4 \%$ Sudeste, $13,0 \%$ na Sul e 7,7\% na Centro-Oeste. A média e mediana de idade das parturientes foi de 25,2 e 24,0 anos, respectivamente, e o desvio-padrão, de 6,3 anos [dado não apresentado em tabela]. A maioria das parturientes incluídas na amostra se autodeclararam como pardas [50,3\%] e possuíam ou estavam cursando o segundo grau [56,7\%], conforme Tabela 1.

A distribuição proporcional das parturientes segundo o sorodiagnóstico da sífilis não apresentou diferença significativa por região de residência $[p=0,108]$. No entanto, segundo faixa etária, raça e cor da pele e escolaridade, observam-se diferenças significativas; a categoria parda representa a maioria das parturientes, mas com diferenças nas proporções - entre as positivas, o percentual é de $53,4 \%$, e entre as negativas, $50,2 \%$. Segundo o nível de escolaridade, entre as positivas, a maioria possuía escolaridade de $5^{\text {a }}$ à $8^{\text {a }}$ série $[42,9 \%$, enquanto as negativas possuíam ou estavam cursando pelo menos o $2^{\circ}$ grau $[56,7 \%]$.

Na Tabela 2, estão apresentadas as informações referentes à assistência prénatal; todas apresentaram diferenças significativas quanto à distribuição proporcional segundo positividade para sífilis. Observa-se que 98,5\% das parturientes realizaram pelo menos uma consulta de pré-natal, percentual semelhante ao observado entre aquelas com resultado negativo para sífilis [98,6\%]; entre as positivas, 89,6\% realizaram pelo menos uma consulta de pré-natal. A maioria das parturientes que realizou pré-natal o fez com pelo menos seis consultas, no entanto, com diferenças significativas entre as proporções, segundo o resultado de sífilis. Entre as parturientes positivas que realizaram o pré-natal, 90,1\% tinham e apresentaram o cartão quando da admissão para o parto, enquanto entre as negativas o percentual foi de $94,9 \%$. Quanto ao trimestre de início do cuidado, as parturientes positivas o iniciaram mais tardiamente quando comparadas às negativas. 
Observa-se associação significativa entre a realização de testes VDRL durante a gestação e o sorodiagnóstico da sífilis quando da admissão para o parto; $85,3 \%$ das positivas para sífilis realizaram pelo menos um teste VDRL durante a gestação, contra 93,5\% das negativas. As parturientes que realizaram dois testes correspondem a $41,4 \%$ e $44,7 \%$ de todas as positivas e negativas, respectivamente [dado não apresentado em tabela]. Os resultados do teste VDRL durante o pré-natal apresentaram associação estatisticamente significativa com a positividade para a sífilis.

Entre as parturientes que apresentaram teste não treponêmico [VDRL] reagente com qualquer titulação, confirmado por teste treponêmico [FTA-Abs ou TPHA] reagente, a prevalência geral da sífilis foi de 0,89\% [IC95\%, 0,79;0,98]. As prevalências segundo as variáveis relacionadas às características epidemiológicas e às informações da assistência pré-natal estão apresentadas na Tabela 3.

As prevalências encontradas em cada região geográfica apresentaram diferenças; as estimativas pontuais das regiões Norte, Nordeste e Centro-Oeste foram superiores à do Brasil, sendo 1,05\%, 1,14\% e 1,20\%, respectivamente; a prevalência da região Sul foi estimada em 0,48\%, e a da região Sudeste, em 0,73\%. Segundo agrupamento por faixa etária, as maiores prevalências foram observadas entre as parturientes de 25 a 49 anos [1,04\%]. Quanto à raça e cor, as maiores prevalências pontuais de sífilis foram observadas entre as parturientes amarelas [1,52\%] e pretas [1,49\%]; as indígenas apresentaram a menor prevalência [0,38\%]. Segundo o grau de escolaridade das parturientes, observa-se um gradiente decrescente das prevalências à medida que aumenta o nível de escolaridade, mostrando uma amplitude de $0,57 \%$ entre aquelas com maior escolaridade $[2 \circ$ grau ou superior] a $3,36 \%$ entre as analfabetas.

A prevalência da sífilis entre as parturientes que realizaram o pré-natal foi estimada em $0,81 \%$. Além disso, observa-se que a prevalência diminui à medida que aumenta o número de consultas; a prevalência de sífilis foi maior entre aquelas que não tinham o cartão pré-natal [4,38\%] e menor entre aquelas que apresentaram o cartão quando do momento da admissão para o parto [0,77\%]; em relação ao trimestre de início do pré-natal, a prevalência é maior quando este se inicia no segundo trimestre de gestação [1,09\%]. 
Segundo a realização dos testes VDRL, entre as parturientes que realizaram o pré-natal, a prevalência da sífilis é 0,74\%; chama atenção a prevalência estimada entre as parturientes que não realizaram o teste VDRL ou aquelas que não apresentaram registro de realização [1,82\%]. Entre as parturientes diagnosticadas durante o pré-natal, 53,05\% mantiveram seu status sorológico quando da admissão para o parto.

As estimativas de razão de prevalências brutas e ajustadas estão apresentadas na Tabela 4. As variáveis de região de residência, realização do prénatal, possuir o cartão pré-natal, realização e resultado de VDRL durante a gestação apresentaram associação positiva com o desfecho no modelo univariado; no entanto, seus efeitos foram suprimidos após o ajuste do modelo multivariado. $O$ modelo final foi definido pelas seguintes variáveis: faixa etária, raça/cor, escolaridade, número de consultas do pré-natal e início do pré-natal.

As parturientes com 25 anos ou mais de idade apresentaram a prevalência de sífilis aumentada em 48,1\% quando comparadas com as jovens [15 a 24 anos]. Constatou-se ainda que, quando comparadas com as parturientes que se autodeclaram brancas, as parturientes amarelas possuíam prevalência da doença aproximadamente três vezes maior, enquanto as pretas, duas vezes maior, e as pardas, 54,1\% maior. O nível de instrução influencia a positividade para sífilis; entre as parturientes analfabetas, a ocorrência da doença é aumentada em cerca de quatro vezes em relação àquelas com maior grau de instrução [ $2^{\circ}$ grau ou superior].

O risco da positividade para sífilis diminui à medida que aumenta o número de consultas de pré-natal; as parturientes que realizaram de uma a cinco consultas apresentam a ocorrência da doença aumentada em 61,5\% quando comparadas com aquelas que realizaram pelo menos seis consultas. As parturientes que iniciaram o pré-natal no $2^{\circ}$ trimestre de gestação apresentaram a ocorrência da sífilis aumentada em $75,8 \%$ quando comparadas com aquelas que o iniciaram no primeiro trimestre.

\section{Discussão}

O presente estudo teve como objetivo estimar a prevalência da sífilis e avaliar características associadas entre parturientes no Brasil. A complexidade deste estudo 
deriva, antes de tudo, da extensão territorial do país. Entre os seus pontos fortes, conta com uma amostra de base institucional; com a coleta de dados por meio padronizado, utilizando questionários aplicados por entrevistadores treinados; e com a coleta de material biológico para o sorodiagnóstico da sífilis.

Contudo, algumas características metodológicas precisam ser discutidas. A estimativa de prevalência da sífilis pode estar subestimada, uma vez que a coleta se deu exclusivamente em maternidades públicas e conveniadas; mulheres que pariram em maternidades privadas ou tiveram parto domiciliar, embora em pequena proporção no Brasil - aproximadamente 2,0\% (78) -, não foram contempladas. Do mesmo modo, não se consideraram as mulheres admitidas nas maternidades para curetagem pós-abortamento, embora a sífilis seja uma causa conhecida de abortamento $(22,48,61)$. No mesmo sentido, a utilização de testes rápidos para a triagem pode representar uma limitação do estudo no que se refere à estimação da prevalência da sífilis, devido à dificuldade de padronização da sua execução; cabe ressaltar, contudo, que esses testes fazem parte da rotina dos serviços de saúde do país. Outra questão é a dificuldade em se avaliar a raça em estudos epidemiológicos (79); no presente estudo, optou-se por utilizar o autorrelato das parturientes para mensurar a distribuição por raça e cor.

A prevalência da sífilis na gravidez encontrada neste estudo foi de $0,89 \%$ [IC95\%, 0,79; 0,98]. De maneira geral, o que se observa é uma diminuição da prevalência da sífilis no Brasil. O último estudo nacional entre parturientes, utilizando a mesma metodologia para a estimação, constatou uma prevalência de 1,6\% [IC95\%, 1,3\%; 1,9\%] em 2004 (80). Outros estudos nacionais também confirmam a diminuição da prevalência; um estudo utilizando como fonte de dados informações coletadas rotineiramente em maternidades do sistema público de saúde estimou a prevalência da sífilis entre parturientes em 1,1\% [IC95\%, 0,9; 1,3] em 2006 (77); em 2011-2012, outro estudo de coorte de base hospitalar estimou em 1,0\% [IC 95\%, $0,8 ; 1,2]$ a prevalência na gestação (81). Obviamente, um dos componentes que contribuiu para a redução da prevalência observada foi a implementação, pelo Ministério da Saúde, de campanhas direcionadas às gestantes em relação aos riscos da sífilis congênita e a necessidade do diagnóstico precoce e tratamento durante o pré-natal (82), fato este evidenciado pela elevada proporção de parturientes que realizaram pelo menos uma consulta no pré-natal [96,9\%]. 
Os resultados regionais, apresentados na Tabela 3 , mostram que a prevalência da sífilis varia de $0,48 \%$ no Sul a $1,20 \%$ na região Centro-Oeste, embora as diferenças não tenham sido estatisticamente significativas, sugerindo que diferenças na prevalência da sífilis se dão por fatores alheios à região de residência das parturientes. Esses resultados estão de acordo com outros estudos brasileiros focalizados: no Estado de Mato Grosso do Sul, em 2002-2003, estimou-se a prevalência da sífilis em 0,8\% [IC95\%, 0,7; 0,9] (83); entre 2004 e 2007, a prevalência da sífilis em gestantes do município de Itajaí, no Estado de Santa Catarina, foi estimada em 0,4\% [IC95\%, 0,3; 0,6] (84); no Estado de Sergipe e no município de Vitória (ES), em 2007, as prevalências da sífilis foram estimadas em 0,9\% [IC95\%, 0,7\%; 1,6\%] (85) e 0,4\% [IC95\%, 0,2\%; 0,9\%] (86), respectivamente; na Amazônia ocidental, em 2008, evidenciou-se 1,0 \% [IC95\%, 0,2; 1,7] de prevalência da sífilis em gestantes (87); no município do Rio de Janeiro, em 20072008, a prevalência de sífilis na gestação foi estimada em 1,9\% [IC95\%, 1,3; 2,6] (88).

No contexto individual, observa-se um maior risco para sífilis entre as parturientes de raça/cor amarela, preta e parda, assim como entre as analfabetas. No Brasil, as pessoas que declaram sua raça ou cor como preta ou parda tendem a possuir uma renda mais baixa e menor escolaridade (89). Entre as hipóteses para explicar tal dinâmica, podem-se destacar as desigualdades nas condições de saúde, ou seja, diferenciais de condições de vida e acesso a cuidados de saúde (81). A relação entre escolaridade e a positividade para sífilis entre parturientes é expressiva no país; quanto maior o período de frequência à escola ou nível de instrução das parturientes, menor a prevalência da sífilis. Vale notar a importância da redução do analfabetismo como mais um instrumento para o controle da sífilis; em 2010, 9,6\% da população brasileira com 15 anos ou mais de idade não sabiam ler ou escrever (90), o que reforça a associação desse agravo às desigualdades sociais. Contudo, outros estudos são necessários para avaliação do cuidado prénatal, especialmente nesses grupos mais vulneráveis.

No que diz respeito ao cuidado pré-natal, o que inclui a promoção da saúde, a prevenção e o tratamento dos problemas que possam ocorrer durante o período gestacional e após o parto e a qualidade da assistência prestada pelo serviço e pelos profissionais de saúde, fator essencial para a adesão das mulheres ao pré- 
natal, é importante notar a interferência que o trimestre de início do pré-natal e o número de consultas exercem sobre a qualidade da assistência pré-natal. Das parturientes estudadas, tão-somente 1,5\% não acessaram os serviços de cuidado pré-natal, percentual inferior aos encontrados em estudos nacionais executados em 2002 e 2006, de 4,4\% e 3,5\%, respectivamente $(91,92)$; em acréscimo a isso, $96,9 \%$ das parturientes realizaram pelo menos uma consulta de pré-natal, sendo $68,8 \%$ seis ou mais consultas, e 93,5\% realizaram pelo menos um exame de VDRL no curso da gestação, resultados estes semelhantes aos observados em outros estudos $(81,84,93-95)$. Apesar dos avanços, o tratamento figura como a grande barreira para o controle da sífilis no país; é impactante a constatação de que mais da metade das parturientes diagnosticadas durante o pré-natal permaneciam infectadas quando da admissão para o parto, havendo terapêutica eficaz disponível na rede pública e evidências para sua irrestrita utilização (24).

Duas características das parturientes encontradas neste estudo consistem em marcadores de uma desvantagem social conhecida: o fato de serem pretas e pardas [62,9\% das entrevistadas] e a baixa escolaridade. Por outro lado, a baixa qualidade da assistência pré-natal parece contribuir ainda mais para agravar a situação no contexto de desigualdades.

A conclusão de que a prevalência da sífilis apresenta uma diminuição no país não significa minimizar a importância das ações de saúde; a sífilis continua a afetar mulheres grávidas, gerando uma importante carga de morbimortalidade infantil, que poderia ser evitada por meio do tratamento adequado. Em 2007, Malta et al. (96), à luz do conhecimento sobre o potencial de intervenção do sistema público de saúde brasileiro, já consideravam as causas de mortes por sífilis reduzíveis e evitáveis, mediante a adequada atenção à mulher na gestação; as evidências apresentadas neste estudo confirmam a efetividade dos serviços de saúde como condição fundamental para o controle da sífilis, em especial, da sífilis congênita.

Em última análise, é possível inferir que o país cumpriu parcialmente a meta da "Iniciativa para a eliminação global da sífilis congênita" de se ter, até 2015, pelo menos $90 \%$ das mulheres grávidas testadas para sífilis; no entanto, a meta de pelo menos $90 \%$ das gestantes soropositivas tratadas adequadamente permanece como um desafio para o sistema público de saúde. A presente análise aponta a 
importância da avaliação e do planejamento das políticas públicas desenvolvidas na área da saúde materno-infantil, visando à implementação de estratégias para o tratamento efetivo e ações correlatas; dessa forma, será possível seguir avançando na redução da prevalência da sífilis no Brasil.

Tabela 1 - Distribuição das parturientes segundo resultado do teste de sífilis e antecedentes epidemiológicos. Brasil, 2010-2011

\begin{tabular}{|c|c|c|c|c|c|c|c|}
\hline \multirow{3}{*}{ Variáveis } & \multicolumn{4}{|c|}{ Resultado de teste de sífilis } & \multirow{2}{*}{\multicolumn{2}{|c|}{ Total }} & \multirow{3}{*}{ p-valor ${ }^{a}$} \\
\hline & \multicolumn{2}{|c|}{ Positivo } & \multicolumn{2}{|c|}{ Negativo } & & & \\
\hline & no & $\%$ & $\mathrm{n}=$ & $\%$ & $\mathrm{n}=$ & $\%$ & \\
\hline Total & 326 & 100,0 & 36387 & 100,0 & 36713 & 100,0 & \\
\hline \multicolumn{8}{|c|}{ Região de residência } \\
\hline Norte & 41 & 12,6 & 3864 & 10,6 & 3905 & 10,6 & \multirow{5}{*}{0,108} \\
\hline Nordeste & 123 & 37,7 & 10638 & 29,2 & 10761 & 29,3 & \\
\hline Sudeste & 105 & 32,2 & 14356 & 39,5 & 14461 & 39,4 & \\
\hline Sul & 23 & 7,1 & 4732 & 13,0 & 4755 & 13,0 & \\
\hline Centro-Oeste & 34 & 10,4 & 2797 & 7,7 & 2831 & 7,7 & \\
\hline \multicolumn{8}{|l|}{ Faixa etária } \\
\hline 15 a 24 anos & 138 & 42,3 & 18498 & 50,8 & 18636 & 50,8 & \multirow{2}{*}{0,002} \\
\hline 25 a 49 anos & 188 & 57,7 & 17889 & 49,2 & 18077 & 49,2 & \\
\hline \multicolumn{8}{|l|}{ Raça/cor } \\
\hline Branca & 61 & 18,7 & 11408 & 31,4 & 11469 & 31,2 & \multirow{6}{*}{0,004} \\
\hline Preta & 69 & 21,2 & 4570 & 12,6 & 4639 & 12,6 & \\
\hline Amarela & 11 & 3,4 & 713 & 2,0 & 724 & 2,0 & \\
\hline Parda & 174 & 53,4 & 18282 & 50,2 & 18456 & 50,3 & \\
\hline Indígena & 1 & 0,3 & 262 & 0,7 & 263 & 0,7 & \\
\hline Ignorado & 11 & 3,4 & 1152 & 3,2 & 1163 & 3,2 & \\
\hline \multicolumn{8}{|l|}{ Escolaridade } \\
\hline $2^{\circ}$ grau ou superior & 118 & 36,2 & 20696 & 56,9 & 20814 & 56,7 & \multirow{5}{*}{$<0,001$} \\
\hline $5^{\mathrm{a}}$ a $8^{\mathrm{a}}$ série & 140 & 42,9 & 12217 & 33,6 & 12357 & 33,7 & \\
\hline $1^{a}$ a $4^{\text {a }}$ série & 52 & 16,0 & 3123 & 8,6 & 3175 & 8,6 & \\
\hline Analfabeta & 10 & 3,1 & 288 & 0,8 & 298 & 0,8 & \\
\hline Ignorado & 6 & 1,8 & 63 & 0,2 & 69 & 0,2 & \\
\hline
\end{tabular}


Tabela 2 - Distribuição das parturientes segundo resultado do teste de sífilis e características relacionadas ao pré-natal. Brasil, 2010-2011

\begin{tabular}{|c|c|c|c|c|c|c|c|}
\hline \multirow{3}{*}{ Variáveis } & \multicolumn{4}{|c|}{ Sorodiagnóstico } & \multirow{2}{*}{\multicolumn{2}{|c|}{ Total }} & \multirow{3}{*}{ p-valor ${ }^{a}$} \\
\hline & \multicolumn{2}{|c|}{ Positivo } & \multicolumn{2}{|c|}{ Negativo } & & & \\
\hline & no & $\%$ & no & $\%$ & no & $\%$ & \\
\hline Total & 326 & 100,0 & 36387 & 100,0 & 36713 & 100,0 & \\
\hline \multicolumn{8}{|l|}{ Fez pré-natal } \\
\hline Sim & 292 & 89,6 & 35870 & 98,6 & 36162 & 98,5 & \multirow{3}{*}{$<0,001$} \\
\hline Não & 32 & 9,8 & 503 & 1,4 & 535 & 1,5 & \\
\hline Sem informação & 2 & 0,6 & 14 & 0,0 & 16 & 0,0 & \\
\hline \multicolumn{8}{|l|}{ Número de consulta ${ }^{b}$} \\
\hline 6 ou mais & 148 & 50,7 & 24730 & 68,9 & 24878 & 68,8 & \multirow{3}{*}{$<0,001$} \\
\hline de 1 a 5 & 122 & 41,8 & 10029 & 28,0 & 10151 & 28,1 & \\
\hline Nenhuma ou sem informação & 22 & 7,5 & 1111 & 3,1 & 1133 & 3,1 & \\
\hline \multicolumn{8}{|l|}{ Cartão pré-natal ${ }^{b}$} \\
\hline Tem e trouxe & 263 & 90,1 & 34040 & 94,9 & 34303 & 94,9 & \multirow{4}{*}{$<0,001$} \\
\hline Tem, mas não trouxe & 17 & 5,8 & 1026 & 2,9 & 1043 & 2,9 & \\
\hline Não tem & 11 & 3,8 & 240 & 0,7 & 251 & 0,7 & \\
\hline Sem informação & 1 & 0,3 & 564 & 1,6 & 565 & 1,6 & \\
\hline \multicolumn{8}{|l|}{ Início do pré-natal ${ }^{b}$} \\
\hline 1ㅇ trimestre & 90 & 30,8 & 18013 & 50,2 & 18103 & 50,1 & \multirow{4}{*}{$<0,001$} \\
\hline $2^{\circ}$ trimestre & 142 & 48,6 & 12931 & 36,0 & 13073 & 36,2 & \\
\hline 3ํ trimestre & 20 & 6,8 & 2524 & 7,0 & 2544 & 7,0 & \\
\hline Sem informação & 40 & 13,7 & 2402 & 6,7 & 2442 & 6,8 & \\
\hline \multicolumn{8}{|l|}{ VDRL no pré-natal ${ }^{b}$} \\
\hline Sim & 249 & 85,3 & 33552 & 93,5 & 33801 & 93,5 & \multirow{2}{*}{$<0,001$} \\
\hline Não ou sem informação & 43 & 14,7 & 2318 & 6,5 & 2361 & 6,5 & \\
\hline \multicolumn{8}{|c|}{ Resultado de VDRL no pré-natal } \\
\hline Negativo & 90 & 36,1 & 32501 & 96,9 & 32591 & 96,4 & \multirow{3}{*}{$<0,001$} \\
\hline Positivo & 148 & 59,4 & 131 & 0,4 & 279 & 0,8 & \\
\hline Sem informação & 11 & 4,4 & 920 & 2,7 & 931 & 2,8 & \\
\hline
\end{tabular}

Fonte: Projeto de verificação de prevalência do HIV e sífilis em parturientes, Brasil

a Teste qui-quadrado de Pearson

b Percentuais calculados em relação às que realizaram pré-natal

c Percentuais calculados em relação às que realizaram pré-natal e pelo menos um dos testes VDRL 
Tabela 3 - Prevalência segundo características associadas a positividade da sífilis no momento do parto. Brasil, 2010-2011

\begin{tabular}{|c|c|c|}
\hline Variáveis & Prevalência (\%) & Intervalo de Confiança (\%) \\
\hline Total & 0,89 & $0,79-0,98$ \\
\hline \multicolumn{3}{|l|}{ Região de residência } \\
\hline Norte & 1,05 & $0,95-1,15$ \\
\hline Nordeste & 1,14 & $1,03-1,25$ \\
\hline Sudeste & 0,73 & $0,64-0,81$ \\
\hline Sul & 0,48 & $0,41-0,55$ \\
\hline Centro-Oeste & 1,20 & $1,09-1,31$ \\
\hline \multicolumn{3}{|l|}{ Faixa etária } \\
\hline 15 a 24 anos & 0,74 & $0,65-0,83$ \\
\hline 25 a 49 anos & 1,04 & $0,94-1,14$ \\
\hline \multicolumn{3}{|l|}{ Raça/cor } \\
\hline Branca & 0,53 & $0,46-0,61$ \\
\hline Preta & 1,49 & $1,36-1,61$ \\
\hline Amarela & 1,52 & $1,39-1,64$ \\
\hline Parda & 0,94 & $0,84-1,04$ \\
\hline Indígena & 0,38 & $0,32-0,44$ \\
\hline Ignorado & 0,86 & $0,77-0,96$ \\
\hline \multicolumn{3}{|l|}{ Escolaridade } \\
\hline $2^{\circ}$ grau ou superior & 0,57 & $0,49-0,64$ \\
\hline $5^{\text {a }}$ a $8^{\text {a }}$ série & 1,13 & $1,02-1,24$ \\
\hline $1^{\text {a }}$ a $4^{\mathrm{a}}$ série & 1,64 & $1,51-1,77$ \\
\hline Analfabeta & 3,36 & $3,17-3,54$ \\
\hline Ignorado & 8,70 & $8,41-8,98$ \\
\hline \multicolumn{3}{|l|}{ Fez pré-natal } \\
\hline Sim & 0,81 & $0,72-0,90$ \\
\hline Não & 5,98 & $5,74-6,22$ \\
\hline Sem informação & 12,50 & $12,16-12,84$ \\
\hline \multicolumn{3}{|l|}{ Número de consultas } \\
\hline 6 ou mais & 0,59 & $0,52-0,67$ \\
\hline de 1 a 5 & 1,20 & $1,09-1,31$ \\
\hline Nenhuma ou sem informação & 1,94 & $1,80-2,08$ \\
\hline \multicolumn{3}{|l|}{ Cartão pré-natal } \\
\hline Tem e trouxe & 0,77 & $0,68-0,86$ \\
\hline Tem, mas não trouxe & 1,63 & $1,50-1,76$ \\
\hline Não tem & 4,38 & $4,17-4,59$ \\
\hline Sem informação & 0,18 & $0,13-0,22$ \\
\hline \multicolumn{3}{|l|}{ Início do pré-natal } \\
\hline 10 trimestre & 0,50 & $0,42-0,57$ \\
\hline 2o trimestre & 1,09 & $0,98-1,19$ \\
\hline 3o trimestre & 0,79 & $0,70-0,88$ \\
\hline Sem informação & 1,64 & $1,51-1,77$ \\
\hline \multicolumn{3}{|l|}{ VDRL no pré-natal } \\
\hline Sim & 0,74 & $0,65-0,82$ \\
\hline Não ou sem informação & 1,82 & $1,68-1,96$ \\
\hline \multicolumn{3}{|l|}{ VDRL no pré-natal } \\
\hline Negativo & 0,28 & $0,22-0,33$ \\
\hline Positivo & 53,05 & $52,51-53,58$ \\
\hline Sem informação & 1,08 & $0,97-1,19$ \\
\hline
\end{tabular}


Tabela 4 - Estimativa do modelo logístico univariado e multivariado das características associadas a positividade da sífilis no momento do parto. Brasil, 2010-2011

\begin{tabular}{|c|c|c|c|c|}
\hline Variáveis & $\begin{array}{c}\text { Estimativa } \\
\text { bruta }\end{array}$ & IC95\% & $\begin{array}{c}\text { Estimativa } \\
\text { ajustada }\end{array}$ & IC95\% \\
\hline \multicolumn{5}{|l|}{ Região de residência } \\
\hline Norte & 1,000 & & NA & \\
\hline Nordeste & 1,074 & $0,758-1,522$ & NA & NA \\
\hline Sudeste & 0,684 & $0,454-1,033$ & NA & NA \\
\hline Sul & 0,451 & $0,290-0,701$ & NA & NA \\
\hline Centro-Oeste & 1,117 & $0,694-1,780$ & NA & NA \\
\hline \multicolumn{5}{|l|}{ Faixa etária } \\
\hline 15 a 24 anos & 1,000 & & 1,000 & \\
\hline 25 a 49 anos & 1,410 & $1,042-1,909$ & 1,481 & $1,067-2,055$ \\
\hline \multicolumn{5}{|l|}{ Raça/cor } \\
\hline Branca & 1,000 & & 1,000 & \\
\hline Preta & 2,824 & $1,745-4,568$ & 2,028 & $1,210-3,398$ \\
\hline Amarela & 2,764 & $1,028-7,431$ & 2,981 & $1,114-7,975$ \\
\hline Parda & 1,776 & $1,198-2,633$ & 1,541 & $1,025-2,317$ \\
\hline Indígena & 0,426 & $0,102-1,781$ & 0,310 & $0,074-1,304$ \\
\hline Ignorado & 1,735 & $0,669-4,502$ & 1,398 & $0,545-3,589$ \\
\hline \multicolumn{5}{|l|}{ Escolaridade } \\
\hline $2^{2}$ grau ou superior & 1,000 & & 1,000 & \\
\hline $5^{\text {a }}$ a $8^{\text {a }}$ série & 1,998 & $1,418-2,815$ & 1,716 & $1,194-2,468$ \\
\hline $1^{\text {a }}$ a $4^{a}$ série & 2,879 & $1,836-4,514$ & 1,921 & $1,172-3,149$ \\
\hline Analfabeta & 5,703 & $2,531-12,852$ & 3,946 & $1,653-9,416$ \\
\hline Ignorado & 16,994 & $5,110-56,521$ & 13,369 & $4,631-38,589$ \\
\hline \multicolumn{5}{|l|}{ Fez pré-natal } \\
\hline Sim & 1,000 & & NA & \\
\hline Não & 7,378 & $4,443-12,251$ & NA & NA \\
\hline Sem informação & 14,570 & $2,327-91,219$ & NA & NA \\
\hline \multicolumn{5}{|l|}{ Número de consultas } \\
\hline 6 ou mais & 1,000 & & 1,000 & \\
\hline de 1 a 5 & 2,023 & $1,461-2,802$ & 1,615 & $1,108-2,355$ \\
\hline Nenhuma ou sem informação & 3,320 & $1,741-6,341$ & 1,956 & $0,889-4,302$ \\
\hline \multicolumn{5}{|l|}{ Cartão pré-natal } \\
\hline Tem e trouxe & 1,000 & & NA & \\
\hline Tem, mas não trouxe & 2,158 & $1,035-4,499$ & NA & NA \\
\hline Não tem & 5,900 & $2,620-13,283$ & NA & NA \\
\hline Sem informação & 4,332 & $3,235-7,668$ & NA & NA \\
\hline \multicolumn{5}{|l|}{ Início do pré-natal } \\
\hline $1^{\circ}$ trimestre & 1,000 & & 1,000 & \\
\hline $2^{\circ}$ trimestre & 2,176 & $1,520-3,114$ & 1,758 & $1,169-2,642$ \\
\hline $3^{\circ}$ trimestre & 1,560 & $0,830-2,934$ & 1,018 & $0,518-1,998$ \\
\hline Sem informação & 3,329 & $1,951-5,680$ & 2,033 & $1,068-3,871$ \\
\hline \multicolumn{5}{|l|}{ VDRL no pré-natal } \\
\hline Sim & 1,000 & & NA & \\
\hline Não ou sem informação & 2,475 & $1,593-3,846$ & NA & NA \\
\hline \multicolumn{5}{|l|}{ VDRL no pré-natal } \\
\hline Negativo & 1,000 & & NA & \\
\hline Positivo & 193,116 & $139,948-266,481$ & NA & NA \\
\hline Sem informação & 4,297 & $1,704-10,833$ & NA & NA \\
\hline
\end{tabular}




\section{CONCLUSÃo}

Diante do que foi exposto até aqui, podemos considerar três grandes conclusões relacionadas às estimativas de parâmetros de significado epidemiológico.

A principal conclusão desta dissertação é a indicação da redução da prevalência da sífilis em parturientes no país, quando da comparação entre os resultados encontrados neste estudo aos do estudo nacional realizado com a mesma metodologia no ano de 2004, sugerindo que as estratégias adotadas pelo governo federal para a redução da sífilis estão expressando resultados positivos.

No entanto, a redução geral da prevalência da sífilis não permite perceber a heterogeneidade dos avanços, especialmente quanto às desigualdades entre grupos sociais e regiões geográficas. De modo geral, as parturientes pretas, amarelas e pardas, além das de menor escolaridade, correm mais risco de infecção pelo $T$. pallidum do que as brancas e de maior escolaridade. Do ponto de vista geográfico, as regiões Norte, Nordeste e Centro-Oeste apresentam estimativas de prevalência da sífilis em parturientes superiores à média nacional; e, embora as diferenças não sejam estatisticamente significativas, indicam que desigualdades regionais permanecem, mesmo considerando os avanços obtidos.

Outra importante conclusão deste trabalho é a demonstração de que quase a totalidade das parturientes atendidas pelo sistema público de saúde [maternidades públicas e conveniadas] acessaram o serviço pré-natal [98,5\%]; mais da metade [68,8\%] destas realizaram seis ou mais consultas; metade [50,1\%] iniciaram o cuidado pré-natal no primeiro trimestre de gestação; e a quase totalidade realizaram e obtiveram o resultado do VDRL no curso da gestação, 93,5\% e 97,2\%, respectivamente. Paradoxalmente, $53,0 \%$ das parturientes permaneciam positivas quando da admissão para o parto, presumidamente, devido à baixa qualidade da assistência pré-natal prestada, demonstrando a principal prioridade para o contínuo avanço da redução da sífilis em gestantes e consequentemente da SC, o tratamento. 
Por fim, este trabalho indica a importância da realização de estudos de abrangência nacional para o monitoramento da magnitude da sífilis e a avaliação das políticas de saúde estabelecidas para o controle do agravo; encerra grande utilidade, representada por estimativas mais próximas da realidade e, por conseguinte, possibilita aos gestores identificar aspectos relevantes para 0 enfrentamento da sífilis quando os casos desse agravo ocorrem e poderiam ser evitados. Espera-se, assim, que as evidências encontradas possam embasar e estimular o debate quanto ao desenvolvimento das ações existentes de prevenção, diagnóstico e tratamento, na perspectiva do fortalecimento da saúde pública e da garantia do compromisso de oferecer melhores condições de vida à população brasileira. 


\section{REFERÊNCIAS}

1. The etiology of syphilis. JAMA : the journal of the American Medical Association. 2014 Nov 12;312(18):1935. PubMed PMID: 25387204.

2. Obladen M. Curse on two generations: a history of congenital syphilis. Neonatology. 2013;103(4):274-80. PubMed PMID: 23485862. Epub 2013/03/15. 3. Waugh M. The centenary of Treponema pallidum: on the discovery of Spirochaeta pallida. International journal of STD \& AIDS. 2005 Sep;16(9):594-5. PubMed PMID: 16176623.

4. Kohl PK, Winzer I. [The 100 years since discovery of Spirochaeta pallida]. Der Hautarzt; Zeitschrift fur Dermatologie, Venerologie, und verwandte Gebiete. 2005 Feb;56(2):112-5. PubMed PMID: 15657727. 100 Jahre Entdeckung der Spirochaeta pallida.

5. Rothschild BM. History of syphilis. Clinical infectious diseases : an official publication of the Infectious Diseases Society of America. 2005 May 15;40(10):145463. PubMed PMID: 15844068.

6. Benzaken AS, Sabido M, Galban E, Pedroza V, Araujo AJ, Peeling RW, et al. Field performance of a rapid point-of-care diagnostic test for antenatal syphilis screening in the Amazon region, Brazil. International journal of STD \& AIDS. 2011 Jan;22(1):15-8. PubMed PMID: 21364061.

7. Benzaken AS, Sabido M, Galban EG, Pedroza V, Vasquez F, Araujo A, et al. Field evaluation of the performance and testing costs of a rapid point-of-care test for syphilis in a red-light district of Manaus, Brazil. Sexually transmitted infections. 2008 Aug;84(4):297-302. PubMed PMID: 18305119.

8. Jafari Y, Peeling RW, Shivkumar S, Claessens C, Joseph L, Pai NP. Are Treponema pallidum Specific Rapid and Point-of-Care Tests for Syphilis Accurate Enough for Screening in Resource Limited Settings? Evidence from a Meta-Analysis. PloS one. 2013 Feb 26;8(2). PubMed PMID: WOS:000315561400003. English.

9. Mabey D, Peeling RW, Ballard R, Benzaken AS, Galban E, Changalucha J, et al. Prospective, multi-centre clinic-based evaluation of four rapid diagnostic tests for syphilis. Sexually transmitted infections. 2006 Dec;82 Suppl 5:v13-6. PubMed PMID: 17215274. Pubmed Central PMCID: 2563907. 
10. Blandford JM, Gift TL, Vasaikar S, Mwesigwa-Kayongo D, Dlali P, Bronzan RN. Cost-effectiveness of on-site antenatal screening to prevent congenital syphilis in rural eastern Cape Province, Republic of South Africa. Sexually transmitted diseases. 2007 Jul;34(7 Suppl):S61-6. PubMed PMID: 17308502.

11. Gianino MM, Dal Conte I, Sciole K, Galzerano M, Castelli L, Zerbi R, et al. Performance and costs of a rapid syphilis test in an urban population at high risk for sexually transmitted infections. Journal of preventive medicine and hygiene. 2007 Dec;48(4):118-22. PubMed PMID: 18557305.

12. Ingraham NR, Jr. The value of penicillin alone in the prevention and treatment of congenital syphilis. Acta dermato-venereologica Supplementum. 1950 Sep 410;31(Suppl. 24):60-87. PubMed PMID: 14829195.

13. Levin CE, Steele M, Atherly D, Garcia SG, Tinajeros F, Revollo R, et al. Analysis of the operational costs of using rapid syphilis tests for the detection of maternal syphilis in Bolivia and Mozambique. Sexually transmitted diseases. 2007 Jul;34(7 Suppl):S47-54. PubMed PMID: 17220812.

14. Schmid GP, Stoner BP, Hawkes S, Broutet N. The need and plan for global elimination of congenital syphilis. Sexually transmitted diseases. $2007 \mathrm{Jul} ; 34$ (7 Suppl):S5-10. PubMed PMID: 17592390.

15. Walker DG, Walker GJ. Forgotten but not gone: the continuing scourge of congenital syphilis. The Lancet infectious diseases. 2002 Jul;2(7):432-6. PubMed PMID: 12127355.

16. Douglas JM, Jr. Penicillin treatment of syphilis: clearing away the shadow on the land. JAMA : the journal of the American Medical Association. 2009 Feb 18;301(7):769-71. PubMed PMID: 19224755. Epub 2009/02/20.

17. Terris-Prestholt F, Watson-Jones D, Mugeye K, Kumaranayake L, Ndeki L, Weiss $\mathrm{H}$, et al. Is antenatal syphilis screening still cost effective in sub-Saharan Africa. Sexually transmitted infections. 2003 Oct;79(5):375-81. PubMed PMID: WOS:000186110900007. English.

18. Fonck K, Claeys P, Bashir F, Bwayo J, Fransen L, Temmerman M. Syphilis control during pregnancy: Effectiveness and sustainability of a decentralized program. American journal of public health. 2001 May;91(5):705-7. PubMed PMID: WOS:000170345300007. English.

19. Kahn JG, Jiwani A, Gomez GB, Hawkes SJ, Chesson HW, Broutet N, et al. The Cost and Cost-Effectiveness of Scaling up Screening and Treatment of Syphilis 
in Pregnancy: A Model. PloS one. 2014 Jan 29;9(1). PubMed PMID: WOS:000330570000156. English.

20. Darmstadt GL, Bhutta ZA, Cousens S, Adam T, Walker N, de Bernis L, et al. Evidence-based, cost-effective interventions: how many newborn babies can we save? Lancet. 2005 Mar 12-18;365(9463):977-88. PubMed PMID: 15767001.

21. Walker DG, Walker GJ. Syphilis: still a major cause of infant mortality. The Lancet infectious diseases. 2012 Apr;12(4):269; author reply 70-1. PubMed PMID: 22459083.

22. Mabey D, Peeling RW. Syphilis, still a major cause of infant mortality. The Lancet infectious diseases. 2011 Sep;11(9):654-5. PubMed PMID: 21683654.

23. 1998 guidelines for treatment of sexually transmitted diseases. Centers for Disease Control and Prevention. MMWR Recommendations and reports : Morbidity and mortality weekly report Recommendations and reports / Centers for Disease Control. 1998 Jan 23;47(RR-1):1-111. PubMed PMID: 9461053.

24. Galvao TF, Silva MT, Serruya SJ, Newman LM, Klausner JD, Pereira MG, et al. Safety of benzathine penicillin for preventing congenital syphilis: a systematic review. PloS one. 2013;8(2):e56463. PubMed PMID: 23437138. Pubmed Central PMCID: 3578834.

25. Brasil. Diretrizes para o Controle da Sífilis Congênita. In: Saúde Md, editor. Primeira Edição ed2005. p. 52p.

26. Brasil. Guia de Vigilância em Saúde. In: Saúde MdSSdVe, editor. 1a edição, versão eletrônica ed. Brasília : Ministério da Saúde: Editora MS; 2014. p. 812. 27. Saúde Md. Diretrizes para controle da sífilis congênita: manual de bolso. 2006. p. 72.

28. Portaria MS/GM N 3.242, 30/12/11, (2011).

29. Brasil. Pré-natal e Puerpério: atenção qualificada e humanizada. Técnicos SANeM, editor2000. 158 p.

30. Brasil. Portaria № 542 de 22 de Dezembro de 1986. In: Saúde Md, editor. 22 de Dezembro de 1986: Diário Oficial da República Federativa do Brasil; 1986. p. 19827.

31. Brasil. Portaria № 5, de 21 de fevereiro de 2006. In: Saúde Md, editor. 21 de fevereiro de 2006: Diário Oficial da República Federativa do Brasil; 2005.

32. Brasil. Portaria № 104, de 25 de janeiro de 2011. In: Saúde Md, editor. 25 de janeiro de 201: Diário Oficial da República Federativa do Brasil; 2011. 
33. Elimination of congenital syphilis. Bulletin of the Pan American Health Organization. 1995 Dec;29(4):364-8. PubMed PMID: 8605527.

34. (Ipea) IdPEA. Objetivos de Desenvolvimento do Milênio: Relatório Nacional de Acompanhamento In: (SPI/MP) SdPelE, editor. 2014: Brasília; 2014. p. 208.

35. OPS/OMS OPdISOMdIS-. Regional Initiative for the Elimination of Mother-to Child Transmission of HIV and Congenital Syphilis in Latin America and the Caribbean: conceptual document. In: CLAP/SMR CLdPSdIMyR-, editor. 2009. 36. Salud OPdl. "Iniciativa Regional para la Eliminación de la Transmisión Maternoinfantil del VIH y de la Sífilis Congénita en América Latina y el Caribe: Estrategia de Monitoreo Regional”. In: Alonso González M, editor. Congénita en América Latina y el Caribe: Estrategia de Monitoreo Regional. 2010: Publicación Científica CLAP/SMR 1574; 2010.

37. Organization PAH. "Regional Initiative for the Elimination of Mother-to-Child Transmission of HIV and Congenital Syphilis in Latin America and the Caribbean: Regional Monitoring Strategy. In: Alonso González M, editor. 2010.

38. Brasil. Plano Operacional: Redução da Transmissão Vertical do HIV e da Sífilis. In: Saúde Md, editor. 2007: Ministério da Saúde; 2007. p. 23.

39. Brasil. Portaria № 399 de 22 de fevereiro de 2006. In: Saúde Md, editor. 22 de fevereiro de 2006: Diário Oficial da República Federativa do Brasil; 2006.

40. Brasil. Portaria № 2.669, de 03 de novembro de 2009 In: Saúde Md, editor. 06 de novembro de 2009 Diário Oficial da República Federativa do Brasil; 2009.

41. Saúde Md. Boletim Epidemiológico de Sífilis. 2012 1517-1159.

42. Boisson E, Nicoll A, Zaba B, Rodrigues LC. Interpreting HIV seroprevalence data from pregnant women. Journal of acquired immune deficiency syndromes and human retrovirology : official publication of the International Retrovirology Association. 1996 Dec 15;13(5):434-9. PubMed PMID: 8970470.

43. Paim J, Travassos C, Almeida C, Bahia L, Macinko J. The Brazilian health system: history, advances, and challenges. Lancet. 2011 May 21;377(9779):1778-97. PubMed PMID: 21561655.

44. Avelleira JCR, Bottino G. Sífilis: diagnóstico, tratamento e controle. Anais brasileiros de dermatologia. 2006;81:111-26.

45. Singh AE, Romanowski B. Syphilis: review with emphasis on clinical, epidemiologic, and some biologic features. Clinical microbiology reviews. 1999 
Apr;12(2):187-209. PubMed PMID: 10194456. Pubmed Central PMCID: 88914. Epub 1999/04/09.

46. Garnett GP, Aral SO, Hoyle DV, Cates W, Jr., Anderson RM. The natural history of syphilis. Implications for the transmission dynamics and control of infection. Sexually transmitted diseases. 1997 Apr;24(4):185-200. PubMed PMID: 9101629. Epub 1997/04/01.

47. Ronald A, Plourde P. Why are syphilis control programs failing? International journal of infectious diseases : IJID : official publication of the International Society for Infectious Diseases. 1998 Jan-Mar;2(3):121-2. PubMed PMID: 9531655.

48. Blencowe H, Cousens S, Kamb M, Berman S, Lawn JE. Lives Saved Tool supplement detection and treatment of syphilis in pregnancy to reduce syphilis related stillbirths and neonatal mortality. BMC public health. 2011;11 Suppl 3:S9. PubMed PMID: 21501460. Pubmed Central PMCID: 3231915.

49. Gjestland T. The Oslo study of untreated syphilis; an epidemiologic investigation of the natural course of the syphilitic infection based upon a re-study of the Boeck-Bruusgaard material. Acta dermato-venereologica Supplementum. 1955;35(Suppl 34):3-368; Annex I-LVI. PubMed PMID: 13301322. Epub 1955/01/01.

50. World Health Organization DoRHaR. Baseline report on global sexually transmitted infection surveillance 2012. 2013 ed. 140 NcW, editor. Geneva: World Health Organization; 2013 2013. 69 p.

51. Hollier LM, Harstad TW, Sanchez PJ, Twickler DM, Wendel GD, Jr. Fetal syphilis: clinical and laboratory characteristics. Obstetrics and gynecology. 2001 Jun;97(6):947-53. PubMed PMID: 11384701. Epub 2001/06/01.

52. Nathan L, Bohman VR, Sanchez PJ, Leos NK, Twickler DM, Wendel GD, Jr. In utero infection with Treponema pallidum in early pregnancy. Prenatal diagnosis. 1997 Feb;17(2):119-23. PubMed PMID: 9061759. Epub 1997/02/01.

53. World Health Organization. Global strategy for the prevention and control of sexually transmitted infections : 2006 - 2015 : breaking the chain of transmission. Geneva: World Health Organization; 2007. 61 p. p.

54. Wicher K, Horowitz HW, Wicher V. Laboratory methods of diagnosis of syphilis for the beginning of the third millennium. Microbes and infection / Institut Pasteur. 1999 Oct;1(12):1035-49. PubMed PMID: 10617935.

55. Workowski KA, Berman S, Centers for Disease C, Prevention. Sexually transmitted diseases treatment guidelines, 2010. MMWR Recommendations and 
reports : Morbidity and mortality weekly report Recommendations and reports / Centers for Disease Control. 2010 Dec 17;59(RR-12):1-110. PubMed PMID: 21160459.

56. Nandwani R, Evans DT. Are you sure it's syphilis? A review of false positive serology. International journal of STD \& AIDS. 1995 Jul-Aug;6(4):241-8. PubMed PMID: 7548285.

57. Stamm LV. Syphilis: antibiotic treatment and resistance. Epidemiology and infection. 2014 Oct 31:1-8. PubMed PMID: 25358292.

58. Stamm LV. Global challenge of antibiotic-resistant Treponema pallidum. Antimicrobial agents and chemotherapy. 2010 Feb;54(2):583-9. PubMed PMID: 19805553. Pubmed Central PMCID: 2812177.

59. Wendel GD, Jr., Sheffield JS, Hollier LM, Hill JB, Ramsey PS, Sanchez PJ. Treatment of syphilis in pregnancy and prevention of congenital syphilis. Clinical infectious diseases : an official publication of the Infectious Diseases Society of America. 2002 Oct 15;35(Suppl 2):S200-9. PubMed PMID: 12353207. Epub 2002/09/28.

60. World Health Organization DoRHaR. Global prevalence and incidence of selected curable sexually transmitted infections : overview and estimates. Geneva: World Health Organization; 2008. 42 p. p.

61. Newman L, Kamb M, Hawkes S, Gomez G, Say L, Seuc A, et al. Global estimates of syphilis in pregnancy and associated adverse outcomes: analysis of multinational antenatal surveillance data. PLoS medicine. 2013;10(2):e1001396. PubMed PMID: 23468598. Pubmed Central PMCID: 3582608. Epub 2013/03/08. 62. World Health Organization. Prevalence and incidence of selected sexually transmitted infections, Chlamydia trachomatis, Neisseria gonorrhoeae, syphilis and trichomonas vaginalis : methods and results used by WHO to generate 2005 estimates. Geneva: World Health Organization; 2011. 38 p. p.

63. Saloojee H, Velaphi S, Goga Y, Afadapa N, Steen R, Lincetto O. The prevention and management of congenital syphilis: an overview and recommendations. Bulletin of the World Health Organization. 2004 Jun;82(6):424-30. PubMed PMID: WOS:000222126900006. English.

64. Global incidence and prevalence of selected curable sexually transmitted infections: 2008. Reproductive health matters. 2012 Nov;20(40):207-9. PubMed PMID: WOS:000313314000027. English. 
65. Bradley H TV, Kamb ML, Newman LM, Garcia PJ, Serruya SJ, et al. Can the Perinatal Information System in Peru be used to measure the proportion of adverse birth outcomes attributable to maternal syphilis infection? Revista panamericana de salud publica = Pan American journal of public health. 2014;36(2)((2)):73-9.

66. Brasil. MonitorAIDS: Sistema de Monitoramento de Indicadores do Programa Nacional de DST e Aids. In: Prevention MdSSdVdSPNdDeACfDCa, editor. Versão 1.0 ed. Brasília: Ministério da Saúde; 2004. p. 100.

67. Szwarcwald ea. Resultados do Estudo Sentinela-Parturiente, 2006: Desafios para o Controle da Sífilis Congênita no Brasil. DST - J bras Doenças Sex Transm. 2007;19(3-4):128-33.

68. Ministério da Saúde SdVeS, Departamento de DST, Aids e Hepatites Virais. Boletim Epidemiológico - Sífilis. 2012 Contract No.: ISSN: 1517-1159.

69. Szwarcwald CL, Barbosa Júnior A, Souza-Júnior PRBd, Lemos KRVd, Frias PGd, Luhm KR, et al. HIV testing during pregnancy: use of secondary data to estimate 2006 test coverage and prevalence in Brazil. Brazilian Journal of Infectious Diseases. 2008;12:167-72.

70. Brasil. Boletim Epidemiológico - Aids e DST. In: Célia Landmann Szwarcwald PRBdSJ, editor. Ano III - no 1 - 01ํㅡ - 26aㅡ de 2006 - semanas epidemiológicas, janeiro a junho de 2006. Ministério da Saúde: Brasília; 2006.

71. Lee J. Odds ratio or relative risk for cross-sectional data? International journal of epidemiology. 1994 Feb;23(1):201-3. PubMed PMID: 8194918.

72. Thompson ML, Myers JE, Kriebel D. Prevalence odds ratio or prevalence ratio in the analysis of cross sectional data: what is to be done? Occupational and environmental medicine. 1998 Apr;55(4):272-7. PubMed PMID: 9624282. Pubmed Central PMCID: 1757577.

73. Zocchetti C, Consonni D, Bertazzi PA. Relationship between prevalence rate ratios and odds ratios in cross-sectional studies. International journal of epidemiology. 1997 Feb;26(1):220-3. PubMed PMID: 9126523.

74. Coutinho LM, Scazufca M, Menezes PR. Methods for estimating prevalence ratios in cross-sectional studies. Revista de saude publica. 2008 Dec;42(6):992-8. PubMed PMID: 19009156.

75. Jafari Y, Peeling RW, Shivkumar S, Claessens C, Joseph L, Pai NP. Are Treponema pallidum specific rapid and point-of-care tests for syphilis accurate enough for screening in resource limited settings? Evidence from a meta-analysis. 
PloS one. 2013;8(2):e54695. PubMed PMID: 23468842. Pubmed Central PMCID: 3582640 .

76. Tucker JD, Bu J, Brown LB, Yin YP, Chen XS, Cohen MS. Accelerating worldwide syphilis screening through rapid testing: a systematic review. The Lancet infectious diseases. 2010 Jun;10(6):381-6. PubMed PMID: 20510278.

77. Szwarcwald CLea. Results of the Sentinel Surveillance Project, 2006: challenges for the control of congenital syphilis in Brazil. DST - J bras Doenças Sex Transm. 2007;19(3-4):128-33.

78. do Carmo Leal M, da Silva AA, Dias MA, da Gama SG, Rattner D, Moreira $\mathrm{ME}$, et al. Birth in Brazil: national survey into labour and birth. Reproductive health. 2012;9:15. PubMed PMID: 22913663. Pubmed Central PMCID: 3500713.

79. Moubarac JC. Persisting problems related to race and ethnicity in public health and epidemiology research. Revista de saude publica. 2013 Feb;47(1):104-15. PubMed PMID: 23703136.

80. Brasil. Boletim Epidemiológico - Aids e DST. Ano III - no 1 - 01a - 26 $6^{\underline{a}}$ de 2006 semanas epidemiológicas, janeiro a junho de 2006 ed. Brasília: Ministério da Saúde; 2006.

81. Domingues RM, Szwarcwald CL, Souza Junior PR, Leal Mdo C. 1,02\% [IC $95 \% 0,84 ; 1,25]$ Prevalence of syphilis in pregnancy and prenatal syphilis testing in Brazil: birth in Brazil study. Revista de saude publica. 2014 Oct;48(5):766-74. PubMed PMID: 25372167. Pubmed Central PMCID: 4211581.

82. Saraceni V, Leal Mdo C. [Evaluation of the effectiveness of the congenital syphilis elimination campaigns on reducing the perinatal morbidity and mortality: Rio de Janeiro, 1999-2000]. Cadernos de saude publica. 2003 Sep-Oct;19(5):1341-9. PubMed PMID: 14666215. Avaliacao da efetividade das campanhas para eliminacao da sifilis congenita na reducao da morbi-mortalidade perinatal: Municipio do Rio de Janeiro, 1999-2000.

83. Figueiro-Filho EA, Senefonte FR, Lopes AH, de Morais OO, Souza Junior VG, Maia TL, et al. [Frequency of HIV-1, rubella, syphilis, toxoplasmosis, cytomegalovirus, simple herpes virus, hepatitis $B$, hepatitis $C$, Chagas disease and HTLV I/II infection in pregnant women of State of Mato Grosso do Sul]. Revista da Sociedade Brasileira de Medicina Tropical. 2007 Mar-Apr;40(2):181-7. PubMed PMID: 17568885. Frequencia das infeccoes pelo HIV-1, rubeola, sifilis, 
toxoplasmose, citomegalovirus, herpes simples, hepatite $\mathrm{B}$, hepatite $\mathrm{C}$, doenca de Chagas e HTLV I/II em gestantes, do Estado de Mato Grosso do Sul.

84. Kupek E, de Oliveira JF. [Vertical transmission of HIV, syphilis and hepatitis B in the municipality with the highest incidence of AIDS in Brazil: a population-based study from 2002 to 2007]. Revista brasileira de epidemiologia = Brazilian journal of epidemiology. 2012 Sep;15(3):478-87. PubMed PMID: 23090297. Transmissao vertical do HIV, da sifilis e da hepatite B no municipio de maior incidencia de AIDS no Brasil: um estudo populacional no periodo de 2002 a 2007.

85. Inagaki AD, Oliveira LA, Oliveira MF, Santos RC, Araujo RM, Alves JA, et al. [Seroprevalence of antibodies for toxoplasmosis, rubella, cytomegalovirus, syphilis and HIV among pregnant women in Sergipe]. Revista da Sociedade Brasileira de Medicina Tropical. 2009 Sep-Oct;42(5):532-6. PubMed PMID: 19967235.

Soroprevalencia de anticorpos para toxoplasmose, rubeola, citomegalovirus, sifilis e HIV em gestantes sergipanas.

86. Miranda AE, Filho ER, Trindade CR, Gouvea GM, Costa DM, Ge Oliveira T, et al. [Prevalence of syphilis and HIV using rapid tests among parturients attended in public maternity hospitals in Vitoria, State of Espirito Santo]. Revista da Sociedade Brasileira de Medicina Tropical. 2009 Jul-Aug;42(4):386-91. PubMed PMID: 19802473. Prevalencia de sifilis e HIV utilizando testes rapidos em parturientes atendidas nas maternidades publicas de Vitoria, Estado do Espirito Santo. 87. Machado Filho AC, Sardinha JF, Ponte RL, Costa EP, da Silva SS, MartinezEspinosa FE. [Prevalence of infection for HIV, HTLV, HBV and of syphilis and chlamydia in pregnant women in a tertiary health unit in the western Brazilian Amazon region]. Revista brasileira de ginecologia e obstetricia : revista da Federacao Brasileira das Sociedades de Ginecologia e Obstetricia. 2010 Apr;32(4):176-83. PubMed PMID: 20625686. Prevalencia de infeccao por HIV, HTLV, VHB e de sifilis e clamidia em gestantes numa unidade de saude terciaria na Amazonia ocidental brasileira.

88. Domingues RM, Saracen V, Hartz ZM, Leal Mdo C. Congenital syphilis: a sentinel event in antenatal care quality. Revista de saude publica. 2013 Feb;47(1):147-56; discussion 57. PubMed PMID: 23703141.

89. Dachs JNW. Determinantes das desigualdades na auto-avaliação do estado de saúde no Brasil: análise dos dados da PNAD/1998. Ciencia \& saude coletiva. 2002;7:641-57. 
90. IBGE IBdGaeE-. Censo Demográfico 2010 2011. Available from:

http://biblioteca.ibge.gov.br/visualizacao/periodicos/93/cd 2010 caracteristicas popu lacao domicilios.pdf.

91. Souza Junior PR, Szwarcwald CL, Barbosa Junior A, Carvalho MF, Castilho EA. [HIV infection during pregnancy: the Sentinel Surveillance Project, Brazil, 2002]. Revista de saude publica. 2004 Dec;38(6):764-72. PubMed PMID: 15608893. Infeccao pelo HIV durante a gestacao: estudo-Sentinela Parturiente, Brasil, 2002. 92. Szwarcwald CL, Barbosa Junior A, Souza-Junior PR, Lemos KR, Frias PG, Luhm KR, et al. HIV testing during pregnancy: use of secondary data to estimate 2006 test coverage and prevalence in Brazil. The Brazilian journal of infectious diseases : an official publication of the Brazilian Society of Infectious Diseases. 2008 Jun;12(3):167-72. PubMed PMID: 18833398.

93. Lima LH, Viana MC. Prevalence and risk factors for HIV, syphilis, hepatitis B, hepatitis $\mathrm{C}$, and HTLV-I/II infection in low-income postpartum and pregnant women in Greater Metropolitan Vitoria, Espirito Santo State, Brazil. Cadernos de saude publica. 2009 Mar;25(3):668-76. PubMed PMID: 19300855.

94. Ramos Jr AN, Matida LH, Saraceni V, Veras MA, Pontes RJ. Control of mother-to-child transmission of infectious diseases in Brazil: progress in HIV/AIDS and failure in congenital syphilis. Cadernos de saude publica. 2007;23 Suppl 3:S3708. PubMed PMID: 17992343.

95. Rodrigues CS, Guimaraes MD, Cesar CC. Missed opportunities for congenital syphilis and HIV perinatal transmission prevention. Revista de saude publica. 2008 Oct;42(5):851-8. PubMed PMID: 18833384.

96. Malta DC, et al. Lista de causas de mortes evitáveis por intervenções do Sistema Único de Saúde do Brasil. Epidemiol Serv Saúde. 2007 dez. 2007;v.16(n.4). 


\section{ANEXO A - TERMO DE CONSENTIMENTO LIVRE E ESCLARECIDO (TCLE)}

\begin{tabular}{|c|c|c|}
\hline & $\begin{array}{c}\text { Projeto } \\
\text { Sentinela } \\
\text { Parturientes }\end{array}$ & \\
\hline RUCS & Х & 88 \\
\hline
\end{tabular}

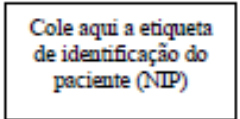

\section{TERMO DE CONSENTIMENTO LIVRE E ESCLARECIDO}

A senhora está sendo convidada a participar de um importante estudo do Ministério da Saúde, com gestantes de todo o país. O objetivo é obter informações sobre o nímero de mulheres com Sifilis e HIV para definição de ações de prevenção e controle dessas infecções, bem como melhoria da qualidade da assistência pré-natal.

A senhora receberá um protocolo com um número de identificação para que seu nome não apareça no estudo.

Seu sangue será coletado por meio de uma picada no dedo (punção digital) para realização de um teste rápido de Sífilis e HIV. Se o resultado for positivo para sífilis, será realizada uma coleta de sangue (punção venosa) para confirmação. O resultado estará disponivel posteniormente na maternidade. Não há riscos na coleta do sangue, porém pode haver desconforto no momento da picada. Todo o material utilizado para a coleta será descartável.

Precisamos também que a senhora responda a um questionánio e nos permita coletar informações adicionais do seu prontuánio e do cartão pré-natal.

No caso de resultado positivo nos testes rápidos, a senhora e seu filho receberão tratamento e acompanhamento imediatos estabelecidos pelo SUS.

Todo o material será unilizado apenas para essa pesquisa. Os resultados desse estudo serão publicados em revistas cientificas onde a senhora não será identificada.

A participação neste estudo é completamente voluntánia e sem interesse financeiro. Se a senhora aceitar participar, garantimos que poderá desistir a qualquer momento, inclusive sem nenhum motivo, bastando para isso, informar sua decisão da maneira mais conveniente. Caso venha a desistir, a senhora continuará a receber atendimento na maternidade sem nenhum prejuizo.

Embora todos os procedimentos a serem executados façam parte da rotina de atendimento para o parto, a senhora receberá assistência a saúde por qualquer dano causado comprovadamente pelo estudo. $\mathrm{E}$, seu consentimento e assinatura não comprometem esse direito.

A senhora poderá perguntar qualquer coisa durante todo o tempo da pesquisa, inclusive, após a publicação, entrando em contato com o responsável pelo estudo:

Gerson Femando Mendes Pereira

Departamento de DST e Aids do Ministério da Saíde

E-mail: gerson.pereira@aids.gov.br-Telefone: (61) 3306-7004

Acredito ter sido suficientemente esclarecida a respeito das informações e das razões que li ou que foram lidas para mim sobre este estudo. Concordo voluntariamente em participar desse estudo e poderei retirar o meu consentimento a qualquer momento, antes ou durante o mesmo, sem penalidade ou prejuizo.

Participante voluntánia do estudo

de

de

Responsável legal (se for o caso)

Entrevistador 


\title{
ANEXO B - DISTRIBUIÇÃO DA AMOSTRA SELECIONADA SEGUNDO ESTRATOS DAS REGIÕES E PORTE POPULACIONAL DO MUNICÍPIO
}

\begin{abstract}
Distribuição da amostra selecionada segundo estratos das regiões e porte populacional do município
\end{abstract}

\begin{tabular}{|c|c|c|c|c|c|}
\hline N.. & Estrato & UF & Município & Instituição & Pop. 2007 \\
\hline 1 & 11 & Acre & Brasiléia & $\begin{array}{l}\text { Hospital de Clínicas } \\
\text { Raimundo Chaar }\end{array}$ & 18386 \\
\hline 2 & 11 & Acre & Sena Madureira & $\begin{array}{l}\text { Hospital João Cancio } \\
\text { Fernandes }\end{array}$ & 34234 \\
\hline 3 & 11 & Amazonas & Autazes & $\begin{array}{l}\text { Unidade Mista de } \\
\text { Autazes }\end{array}$ & 30333 \\
\hline 4 & 11 & Amazonas & Benjamin Constant & $\begin{array}{l}\text { Un. Mista de } \\
\text { Benjamin Constant }\end{array}$ & 27281 \\
\hline 5 & 11 & Amazonas & Eirunepé & $\begin{array}{l}\text { Unidade Mista de } \\
\text { Eirunepé }\end{array}$ & 30751 \\
\hline 6 & 11 & Amazonas & Manicore & $\begin{array}{l}\text { Unidade Mista de } \\
\text { Manicore }\end{array}$ & 38186 \\
\hline 7 & 11 & Amazonas & Tabatinga & $\begin{array}{l}\text { Hospital de } \\
\text { Guarnição de } \\
\text { Tabatinga }\end{array}$ & 46186 \\
\hline 8 & 11 & Pará & Alenquer & $\begin{array}{l}\text { Hospital Santo } \\
\text { Antônio }\end{array}$ & 39383 \\
\hline 9 & 11 & Pará & Pacajá & $\begin{array}{l}\text { Unidade Mista de } \\
\text { Pacajá }\end{array}$ & 31525 \\
\hline 10 & 11 & Pará & Paragominas & Hospital São Paulo & 39383 \\
\hline 11 & 11 & Pará & Porto de Moz & $\begin{array}{l}\text { Hospital Municipal } \\
\text { Ana Nery }\end{array}$ & 30847 \\
\hline 12 & 11 & Pará & Santana do Araguaia & $\begin{array}{l}\text { Hospital Mun N } \\
\text { Senhora De Lourdes }\end{array}$ & 44233 \\
\hline 13 & 11 & Pará & São Miguel do Guama & $\begin{array}{l}\text { Hosp.Mun. de São } \\
\text { Miguel do Guama }\end{array}$ & 48541 \\
\hline 14 & 11 & Tocantins & Miracema do Tocantins & $\begin{array}{l}\text { Hospital de Miracema } \\
\text { do Tocantins }\end{array}$ & 28809 \\
\hline 15 & 11 & Tocantins & Paraíso do Tocantins & $\begin{array}{l}\text { Hosp. de Referência } \\
\text { Dr. Alfredo Oliveira } \\
\text { Barros }\end{array}$ & 43253 \\
\hline 16 & 12 & Acre & Rio Branco & $\begin{array}{l}\text { Maternidade e Clínica } \\
\text { de Mulheres Bárbara } \\
\text { Heliodora }\end{array}$ & 322449 \\
\hline 17 & 12 & Acre & Rio Branco & $\begin{array}{l}\text { Hospital Santa } \\
\text { Juliana }\end{array}$ & 322449 \\
\hline 18 & 12 & Amazonas & Coari & $\begin{array}{l}\text { Hospital Regional de } \\
\text { Coari Prof. Dr. Odair } \\
\text { Carlos Geraldo }\end{array}$ & 90603 \\
\hline 19 & 12 & Pará & Bragança & $\begin{array}{l}\text { Hospital Geral de } \\
\text { Bragança }\end{array}$ & 105258 \\
\hline 20 & 12 & Pará & Marituba & $\begin{array}{l}\text { Hospital Dda Divina } \\
\text { Providência }\end{array}$ & 105426 \\
\hline
\end{tabular}




\begin{tabular}{|c|c|c|c|c|c|}
\hline NN.. & Estrato & UF & Município & Instituição & Pop. 2007 \\
\hline 21 & 12 & Pará & Moju & $\begin{array}{l}\text { Hospital e } \\
\text { Maternidade Divino } \\
\text { Espírito Santo }\end{array}$ & 63625 \\
\hline 22 & 12 & Pará & Parauapebas & $\begin{array}{l}\text { Hospital Municipal de } \\
\text { Parauapebas Hmp }\end{array}$ & 98796 \\
\hline 23 & 12 & Pará & Santarém & $\begin{array}{l}\text { Maternidade Irmã } \\
\text { Dulce }\end{array}$ & 278118 \\
\hline 24 & 12 & Pará & Tucuruí & $\begin{array}{l}\text { Hospital Municipal de } \\
\text { Tucuruí }\end{array}$ & 89690 \\
\hline 25 & 12 & Pará & Uruara & $\begin{array}{l}\text { Hospital Municipal de } \\
\text { Uruara }\end{array}$ & 62103 \\
\hline 26 & 12 & Rondônia & Cacoal & $\begin{array}{l}\text { Hospital Municipal } \\
\text { Materno Infantil } \\
\text { Cacoal }\end{array}$ & 76854 \\
\hline 27 & 12 & Rondônia & Ji-paraná & $\begin{array}{l}\text { Hospital Municipal Ji- } \\
\text { paraná }\end{array}$ & 114459 \\
\hline 28 & 12 & Rondônia & Porto Velho & $\begin{array}{l}\text { Hospital Maternidade } \\
\text { Mãe Esperança }\end{array}$ & 387964 \\
\hline 29 & 12 & Roraima & Boa Vista & $\begin{array}{l}\text { Hospital Materno } \\
\text { Infantil N. Senhora de } \\
\text { Nazareth }\end{array}$ & 257071 \\
\hline 30 & 12 & Tocantins & Palmas & $\begin{array}{l}\text { Hospital Dona Regina } \\
\text { Siqueira Campos }\end{array}$ & 233516 \\
\hline 31 & 13 & Amazonas & Manaus & $\begin{array}{l}\text { Maternidade da } \\
\text { Alvorada }\end{array}$ & 1731993 \\
\hline 32 & 13 & Amazonas & Manaus & $\begin{array}{l}\text { Complexo Hospitalar } \\
\text { Fleming }\end{array}$ & 1731993 \\
\hline 33 & 13 & Amazonas & Manaus & $\begin{array}{l}\text { Maternidade Cidade } \\
\text { Nova Dnazira Daou }\end{array}$ & 1731993 \\
\hline 34 & 13 & Amazonas & Manaus & $\begin{array}{l}\text { Maternidade Balbina } \\
\text { Mestrinho }\end{array}$ & 1731993 \\
\hline 35 & 13 & Amazonas & Manaus & $\begin{array}{l}\text { Maternidade } \\
\text { Municipal Dr. Moura } \\
\text { Tapajós }\end{array}$ & 1731993 \\
\hline 36 & 13 & Amazonas & Manaus & $\begin{array}{l}\text { Maternidade Galileia } \\
\text { Azilda da Silva } \\
\text { Marreiro }\end{array}$ & 1731993 \\
\hline 37 & 13 & Pará & Ananindeua & Inisa & 513884 \\
\hline 38 & 13 & Pará & Ananindeua & $\begin{array}{l}\text { Hospital e } \\
\text { Maternidade Camilo } \\
\text { Salgado Ltda. }\end{array}$ & 513884 \\
\hline 39 & 13 & Pará & Ananindeua & $\begin{array}{l}\text { Hospital e } \\
\text { Maternidade Frei } \\
\text { Samarate }\end{array}$ & 513884 \\
\hline 40 & 13 & Pará & Ananindeua & Hospital Anita Gerosa & 513884 \\
\hline 41 & 13 & Pará & Belém & $\begin{array}{l}\text { Hospital Ordem } \\
\text { Terceira }\end{array}$ & 513884 \\
\hline 42 & 13 & Pará & Belém & $\begin{array}{l}\text { Hospital e } \\
\text { Maternidade Santa } \\
\text { Bárbara }\end{array}$ & 1450699 \\
\hline 43 & 13 & Pará & Belém & Maternidade do Povo & 1450699 \\
\hline 44 & 13 & Pará & Belém & Hospital D. Luiz I & 1450699 \\
\hline 45 & 13 & Pará & Belém & $\begin{array}{l}\text { Santa Casa de } \\
\text { Misericórdia do Pará }\end{array}$ & 1450699 \\
\hline 46 & 21 & Bahia & Barra Da Estiva & $\begin{array}{l}\text { Hospital Susy } \\
\text { Zanfretta }\end{array}$ & 30538 \\
\hline
\end{tabular}




\begin{tabular}{|c|c|c|c|c|c|}
\hline N.ㅇ & Estrato & UF & Município & Instituição & Pop. 2007 \\
\hline 47 & 21 & Bahia & Nazaré & $\begin{array}{l}\text { Hospital Gonçalves } \\
\text { Martins }\end{array}$ & 26714 \\
\hline 48 & 21 & Bahia & Pojuca & $\begin{array}{l}\text { Maternidade Maria } \\
\text { Luiza Dias Laudano }\end{array}$ & 29328 \\
\hline 49 & 21 & Bahia & Ruy Barbosa & $\begin{array}{l}\text { Hospital Regional de } \\
\text { Ruy Barbosa }\end{array}$ & 28157 \\
\hline 50 & 21 & Ceará & Ipu & $\begin{array}{l}\text { Matern. Hosp. Infant. } \\
\text { Dr. Franc Araújo }\end{array}$ & 41260 \\
\hline 51 & 21 & Ceará & São Benedito & $\begin{array}{l}\text { Hospital Municipal de } \\
\text { São Benedito }\end{array}$ & 42611 \\
\hline 52 & 21 & Maranhão & Barreirinhas & Hospital São Lucas & 46729 \\
\hline 53 & 21 & Maranhão & Pio Xii & $\begin{array}{l}\text { Unidade Mista São } \\
\text { Sebastião }\end{array}$ & 29577 \\
\hline 54 & 21 & Maranhão & Zé Doca & $\begin{array}{l}\text { Unidade Mista de Zé } \\
\text { Doca }\end{array}$ & 10616 \\
\hline 55 & 21 & Paraíba & Monteiro & $\begin{array}{l}\text { Hospital Regional } \\
\text { Santa Filomena }\end{array}$ & 28228 \\
\hline 56 & 21 & Pernambuco & Custodia & $\begin{array}{l}\text { Unidade Mista } \\
\text { Elizabete Barbosa }\end{array}$ & 30918 \\
\hline 57 & 21 & Pernambuco & São Jose Do Egito & $\begin{array}{l}\text { Um. Mista Maria } \\
\text { Rafael de Siqueira }\end{array}$ & 30141 \\
\hline 58 & 21 & Piauí & São Raimundo Nonato & $\begin{array}{l}\text { H. Reg. Sen. C. } \\
\text { Ferraz }\end{array}$ & 29747 \\
\hline 59 & 21 & Rio Grande do Norte & Pau Dos Ferros & $\begin{array}{l}\text { Maternidade Santa } \\
\text { Luiza de Marillac }\end{array}$ & 28103 \\
\hline 60 & 21 & Sergipe & Nossa Senhora da Glória & $\begin{array}{l}\text { Hospital Regional } \\
\text { João Alves Filho }\end{array}$ & 29829 \\
\hline 61 & 22 & Alagoas & Palmeira dos Índios & $\begin{array}{l}\text { Hospital Regional } \\
\text { Santa Rita e } \\
\text { Maternidade Santa } \\
\text { Olímpia }\end{array}$ & 69970 \\
\hline 62 & 22 & Alagoas & União dos Palmares & $\begin{array}{l}\text { Hospital Geral de } \\
\text { União }\end{array}$ & 59637 \\
\hline 63 & 22 & Bahia & Barreiras & $\begin{array}{l}\text { Maternidade } \\
\text { Municipal de } \\
\text { Barreiras }\end{array}$ & 141781 \\
\hline 64 & 22 & Bahia & Itabuna & $\begin{array}{l}\text { Hospital Manoel } \\
\text { Novaes }\end{array}$ & 206339 \\
\hline 65 & 22 & Bahia & Monte Santo & $\begin{array}{l}\text { Hospital Municipal } \\
\text { Monsenhor } \\
\text { Berenguer }\end{array}$ & 57325 \\
\hline 66 & 22 & Bahia & Santo Amaro & $\begin{array}{l}\text { Hospital Maternidade } \\
\text { de Santo Amaro }\end{array}$ & 62022 \\
\hline 67 & 22 & Ceará & Itapipoca & $\begin{array}{l}\text { Hospital Maternidade } \\
\text { São Vicente de Paulo }\end{array}$ & 108921 \\
\hline 68 & 22 & Ceará & Sobral & $\begin{array}{l}\text { Hospital Dr. Estevam } \\
\text { Ponte }\end{array}$ & 178916 \\
\hline 69 & 22 & Ceará & Sobral & $\begin{array}{l}\text { Santa Casa de } \\
\text { Misericórdia de } \\
\text { Sobral }\end{array}$ & 178916 \\
\hline 70 & 22 & Maranhão & Balsas & Hospital São José & 75914 \\
\hline 71 & 22 & Maranhão & Buriticupu & $\begin{array}{l}\text { Hospital Municipal } \\
\text { Pedro Neiva de } \\
\text { Santana }\end{array}$ & 68632 \\
\hline 72 & 22 & Maranhão & Caxias & $\begin{array}{l}\text { Hosp. Munic. } \\
\text { Materno Infantil Sinhá } \\
\text { Castelo }\end{array}$ & 145088 \\
\hline
\end{tabular}




\begin{tabular}{|c|c|c|c|c|c|}
\hline $\mathrm{N} . \stackrel{0}{ }$ & Estrato & UF & Município & Instituição & Pop. 2007 \\
\hline 73 & 22 & Pernambuco & Paulista & $\begin{array}{l}\text { Hospital Central de } \\
\text { Paulista }\end{array}$ & 305408 \\
\hline 74 & 22 & Sergipe & Lagarto & $\begin{array}{l}\text { Maternidade Zacarias } \\
\text { Júnior }\end{array}$ & 92857 \\
\hline 75 & 22 & Sergipe & Nossa Senhora do Socorro & $\begin{array}{l}\text { Hospital Regional } \\
\text { José Franco }\end{array}$ & 186216 \\
\hline 76 & 23 & Bahia & Salvador & $\begin{array}{l}\text { Hospital Geral João } \\
\text { Batista Caribe }\end{array}$ & 2754950 \\
\hline 77 & 23 & Bahia & Salvador & $\begin{array}{l}\text { Maternidade Albert } \\
\text { Sabin }\end{array}$ & 2754950 \\
\hline 78 & 23 & Bahia & Salvador & $\begin{array}{l}\text { Instituto de } \\
\text { Perinatologia da } \\
\text { Bahia }\end{array}$ & 2754950 \\
\hline 79 & 23 & Bahia & Salvador & $\begin{array}{l}\text { Maternidade } \\
\text { Professor Jose Maria } \\
\text { de Magalhães Neto }\end{array}$ & 2754950 \\
\hline 80 & 23 & Ceará & Fortaleza & $\begin{array}{l}\text { Hospital Aguanambi } \\
\text { Gomes da Frota }\end{array}$ & 2458545 \\
\hline 81 & 23 & Ceará & Fortaleza & $\begin{array}{l}\text { Hospital Distrital } \\
\text { Gonzaga Mota } \\
\text { Messejana }\end{array}$ & 2458545 \\
\hline 82 & 23 & Ceará & Fortaleza & $\begin{array}{l}\text { HGCC - Hospital } \\
\text { Geral Dr. Cesar Cals }\end{array}$ & 2458545 \\
\hline 83 & 23 & Maranhão & São Luís & $\begin{array}{l}\text { Maternidade Maria do } \\
\text { Amparo e Amb. Maria } \\
\text { da Vitória }\end{array}$ & 1017772 \\
\hline 84 & 23 & Pernambuco & Jaboatão dos Guararapes & $\begin{array}{l}\text { Hospital Memorial } \\
\text { Guararapes }\end{array}$ & 661901 \\
\hline 85 & 23 & Pernambuco & Recife & $\begin{array}{l}\text { Us } 153 \text { Policlínica e } \\
\text { Maternidade Arnaldo } \\
\text { Marques }\end{array}$ & 1528970 \\
\hline 86 & 23 & Pernambuco & Recife & $\begin{array}{l}\text { Us } 167 \text { Unidade } \\
\text { Mista Prof. Barros } \\
\text { Lima }\end{array}$ & 1528970 \\
\hline 87 & 23 & Piauí & Teresina & $\begin{array}{l}\text { Unidade Mista de } \\
\text { Saúde D. Antônio } \\
\text { Pedreira de A. } \\
\text { Martins }\end{array}$ & 815060 \\
\hline 88 & 23 & Rio Grande do Norte & Natal & $\begin{array}{l}\text { Hospital Santa } \\
\text { Catarina }\end{array}$ & 801665 \\
\hline 89 & 23 & Sergipe & Aracaju & Clínica Santa Helena & 511893 \\
\hline 90 & 23 & Sergipe & Aracaju & Clinica Santa Izabel & 511893 \\
\hline 91 & 31 & Espírito Santo & Itapemirim & $\begin{array}{l}\text { Hospital Maternidade } \\
\text { Santa Helena }\end{array}$ & 33448 \\
\hline 92 & 31 & Minas Gerais & Almenara & $\begin{array}{l}\text { Hospital Deraldo } \\
\text { Guimarães }\end{array}$ & 36827 \\
\hline 93 & 31 & Minas Gerais & Bocaiúva & $\begin{array}{l}\text { Hospital Municipal de } \\
\text { Bocaiúva }\end{array}$ & 45732 \\
\hline 94 & 31 & Minas Gerais & Capelinha & $\begin{array}{l}\text { Hospital Municipal } \\
\text { São Vicente De } \\
\text { Paula Capelinha }\end{array}$ & 36056 \\
\hline 95 & 31 & Minas Gerais & Diamantina & $\begin{array}{l}\text { Hospital de Nossa } \\
\text { Senhora da Saúde }\end{array}$ & 44222 \\
\hline 96 & 31 & Minas Gerais & Guanhães & $\begin{array}{l}\text { Hospital Regional } \\
\text { Imaculada Conceição }\end{array}$ & 30084 \\
\hline 97 & 31 & Minas Gerais & Inhapim & $\begin{array}{l}\text { Hospital São } \\
\text { Sebastião de Inhapim }\end{array}$ & 24370 \\
\hline
\end{tabular}




\begin{tabular}{|c|c|c|c|c|c|}
\hline NN.. & Estrato & UF & Município & Instituição & Pop. 2007 \\
\hline 98 & 31 & Minas Gerais & Lagoa Santa & $\begin{array}{l}\text { Lagoa Santa - } \\
\text { Hospital Lindouro } \\
\text { Avelar }\end{array}$ & 47812 \\
\hline 99 & 31 & Minas Gerais & Machado & $\begin{array}{l}\text { Irmandade da Santa } \\
\text { Casa de Caridade de } \\
\text { Machado }\end{array}$ & 38420 \\
\hline 100 & 31 & Minas Gerais & Manga & Hospital Funrural & 24304 \\
\hline 101 & 31 & Minas Gerais & Salinas & $\begin{array}{l}\text { Hospital Municipal Dr. } \\
\text { Oswaldo Prediliano } \\
\text { Santana }\end{array}$ & 38141 \\
\hline 102 & 31 & Minas Gerais & Santos Dumont & $\begin{array}{l}\text { Hospital de Santos } \\
\text { Dumont }\end{array}$ & 48340 \\
\hline 103 & 31 & Rio de Janeiro & Miguel Pereira & $\begin{array}{l}\text { Hospital Santo } \\
\text { Antônio da Estiva }\end{array}$ & 27694 \\
\hline 104 & 31 & Rio de Janeiro & Paracambi & $\begin{array}{l}\text { Hospital Evangélico } \\
\text { de Paracambi }\end{array}$ & 43918 \\
\hline 105 & 31 & São Paulo & Capão Bonito & $\begin{array}{l}\text { Santa Casa de } \\
\text { Capão Bonito }\end{array}$ & 46976 \\
\hline 106 & 32 & Espírito Santo & Colatina & $\begin{array}{l}\text { Hospital e } \\
\text { Maternidade São } \\
\text { José }\end{array}$ & 113052 \\
\hline 107 & 32 & Minas Gerais & Ipatinga & $\begin{array}{l}\text { Hospital Marcio } \\
\text { Cunha }\end{array}$ & 240084 \\
\hline 108 & 32 & Minas Gerais & Montes Claros & $\begin{array}{l}\text { Hospital Aroldo } \\
\text { Tourinho }\end{array}$ & 355342 \\
\hline 109 & 32 & Minas Gerais & Montes Claros & $\begin{array}{l}\text { Santa Casa de } \\
\text { Montes Claros }\end{array}$ & 355342 \\
\hline 110 & 32 & Minas Gerais & Unai & $\begin{array}{l}\text { Hospital Municipal Dr. } \\
\text { Joaquim Brochado }\end{array}$ & 77184 \\
\hline 111 & 32 & Rio de Janeiro & Cabo Frio & $\begin{array}{l}\text { Hospital São José } \\
\text { Operário }\end{array}$ & 171448 \\
\hline 112 & 32 & Rio de Janeiro & Resende & Apmir & 122020 \\
\hline 113 & 32 & Rio de Janeiro & Saquarema & $\begin{array}{l}\text { Hospital Municipal } \\
\text { Nossa Senhora de } \\
\text { Nazareth }\end{array}$ & 64859 \\
\hline 114 & 32 & São Paulo & Araraquara & $\begin{array}{l}\text { Santa Casa de } \\
\text { Araraquara }\end{array}$ & 202251 \\
\hline 115 & 32 & São Paulo & Itapecerica Da Serra & $\begin{array}{l}\text { Pronto Socorro e } \\
\text { Maternidade de } \\
\text { Itapecerica da Serra }\end{array}$ & 167158 \\
\hline 116 & 32 & São Paulo & Itapetininga & $\begin{array}{l}\text { Hospital Regional de } \\
\text { Itapetininga }\end{array}$ & 145747 \\
\hline 117 & 32 & São Paulo & Itaquaquecetuba & $\begin{array}{l}\text { Hospital Geral de } \\
\text { Itaquaquecetuba }\end{array}$ & 364811 \\
\hline 118 & 32 & São Paulo & Moji-Guaçu & $\begin{array}{l}\text { Santa Casa de Mogi- } \\
\text { Guaçu }\end{array}$ & 144177 \\
\hline 119 & 32 & São Paulo & Registro & $\begin{array}{l}\text { Hospital São João } \\
\text { Registro }\end{array}$ & 57836 \\
\hline 120 & 32 & São Paulo & São Roque & $\begin{array}{l}\text { Hospital de São } \\
\text { Roque }\end{array}$ & 74855 \\
\hline 121 & 33 & Minas Gerais & Belo Horizonte & $\begin{array}{l}\text { Hospital Julia } \\
\text { Kubitschek }\end{array}$ & 2424295 \\
\hline 122 & 33 & Minas Gerais & Belo Horizonte & $\begin{array}{l}\text { Maternidade Odete } \\
\text { Valadares }\end{array}$ & 2424295 \\
\hline 123 & 33 & Minas Gerais & Belo Horizonte & $\begin{array}{l}\text { Hospital Sofia } \\
\text { Feldman }\end{array}$ & 2424295 \\
\hline 124 & 33 & Minas Gerais & Contagem & Maternidade & 613250 \\
\hline
\end{tabular}




\begin{tabular}{|c|c|c|c|c|c|}
\hline N. .9 & Estrato & UF & Município & Instituição & Pop. 2007 \\
\hline & & & & $\begin{array}{l}\text { Municipal de } \\
\text { Contagem }\end{array}$ & \\
\hline 125 & 33 & Rio de Janeiro & Nova Iguaçu & Hospital de Iguaçu & 858150 \\
\hline 126 & 33 & Rio de Janeiro & Rio de Janeiro & $\begin{array}{l}\text { Fiotec IFF - Instituto } \\
\text { Fernandes Fiqueira }\end{array}$ & 6178762 \\
\hline 127 & 33 & Rio de Janeiro & Rio de Janeiro & $\begin{array}{l}\text { MS Hospital Geral de } \\
\text { Bonsucesso }\end{array}$ & 6178762 \\
\hline 128 & 33 & Rio de Janeiro & Rio De Janeiro & $\begin{array}{l}\text { Sms Rio Hospital } \\
\text { Maternidade Carmela } \\
\text { Dutra }\end{array}$ & 6178762 \\
\hline 129 & 33 & São Paulo & Diadema & $\begin{array}{l}\text { Hospital Público de } \\
\text { Diadema }\end{array}$ & 401113 \\
\hline 130 & 33 & São Paulo & Guarulhos & $\begin{array}{l}\text { Hospital Geral de } \\
\text { Guarulhos }\end{array}$ & 1315059 \\
\hline 131 & 33 & São Paulo & São Paulo & $\begin{array}{l}\text { Hosp. Mun. Ver. José } \\
\text { Storopolli }\end{array}$ & 11104712 \\
\hline 132 & 33 & São Paulo & São Paulo & $\begin{array}{l}\text { Hospital de } \\
\text { Sapopemba }\end{array}$ & 11104712 \\
\hline 133 & 33 & São Paulo & São Paulo & Hospital Regional Sul & 11104712 \\
\hline 134 & 33 & São Paulo & São Paulo & $\begin{array}{l}\text { Hosp. da Sta. Casa } \\
\text { de Sto. Amaro }\end{array}$ & 11104712 \\
\hline 135 & 33 & São Paulo & São Paulo & $\begin{array}{l}\text { Hosp. Mun. } \\
\text { Cachoeirinha - Mario } \\
\text { de Moraes A. Silva }\end{array}$ & 11104712 \\
\hline 136 & 41 & Paraná & Cornélio Procópio & $\begin{array}{l}\text { Santa Casa de } \\
\text { Cornélio Procópio }\end{array}$ & 47045 \\
\hline 137 & 41 & Paraná & Laranjeiras do Sul & Hospital São Lucas & 30382 \\
\hline 138 & 41 & Paraná & Pinhão & Hospital Santa Cruz & 27873 \\
\hline 139 & 41 & Rio Grande do Sul & Capão da Canoa & $\begin{array}{l}\text { Hospital Beneficente } \\
\text { Santa Luzia }\end{array}$ & 39879 \\
\hline 140 & 41 & Rio Grande do Sul & São Jerônimo & $\begin{array}{l}\text { Hospital de Caridade } \\
\text { São Jerônimo }\end{array}$ & 19983 \\
\hline 141 & 41 & Rio Grande do Sul & Torres & $\begin{array}{l}\text { Hospital Beneficente } \\
\text { Nossa Senhora Dos } \\
\text { Navegantes }\end{array}$ & 35526 \\
\hline 142 & 41 & Rio Grande do Sul & Tramandaí & Hospital Tramandaí & 40324 \\
\hline 143 & 41 & Santa Catarina & Curitibanos & $\begin{array}{l}\text { Hospital Hélio Anjos } \\
\text { Ortiz }\end{array}$ & 38380 \\
\hline 144 & 41 & Santa Catarina & Indaial & $\begin{array}{l}\text { Hospital Beatriz } \\
\text { Ramos }\end{array}$ & 48732 \\
\hline 145 & 41 & Santa Catarina & Ituporanga & Hospital Bom Jesus & 20176 \\
\hline 146 & 41 & Santa Catarina & Joaçaba & $\begin{array}{l}\text { Hospital Universitário } \\
\text { Santa Terezinha }\end{array}$ & 25132 \\
\hline 147 & 41 & Santa Catarina & Porto União & $\begin{array}{l}\text { Hospital de Caridade } \\
\text { São Braz }\end{array}$ & 33538 \\
\hline 148 & 41 & Santa Catarina & Rio Negrinho & Hospital Rio Negrinho & 45574 \\
\hline 149 & 41 & Santa Catarina & São Francisco Do Sul & Hospital de Caridade & 39667 \\
\hline 150 & 41 & Santa Catarina & Xanxerê & $\begin{array}{l}\text { Hospital Regional } \\
\text { São Paulo Assec }\end{array}$ & 41383 \\
\hline 151 & 42 & Paraná & Castro & $\begin{array}{l}\text { Hospital Anna Fiorillo } \\
\text { Menarim }\end{array}$ & 70361 \\
\hline 152 & 42 & Paraná & Colombo & $\begin{array}{l}\text { Hospital Maternidade } \\
\text { Alto Maracanã }\end{array}$ & 239102 \\
\hline 153 & 42 & Paraná & Paranaguá & $\begin{array}{l}\text { Hospital Regional do } \\
\text { Litoral }\end{array}$ & 151047 \\
\hline
\end{tabular}




\begin{tabular}{|c|c|c|c|c|c|}
\hline NN.. & Estrato & UF & Município & Instituição & Pop. 2007 \\
\hline 154 & 42 & Paraná & Ponta Grossa & $\begin{array}{l}\text { Santana Unimed } \\
\text { Hospital }\end{array}$ & 309709 \\
\hline 155 & 42 & Paraná & São Jose dos Pinhais & $\begin{array}{l}\text { Hospital Municipal Dr. } \\
\text { Attilio Talamini }\end{array}$ & 269704 \\
\hline 156 & 42 & Paraná & Umuarama & $\begin{array}{l}\text { Maternidade } \\
\text { Municipal de } \\
\text { Umuarama }\end{array}$ & 96863 \\
\hline 157 & 42 & Rio Grande do Sul & Bagé & $\begin{array}{l}\text { Santa Casa de } \\
\text { Caridade de Bagé }\end{array}$ & 123611 \\
\hline 158 & 42 & Rio Grande do Sul & Erechim & $\begin{array}{l}\text { Fundação Hospitalar } \\
\text { Santa Terezinha de } \\
\text { Erechim }\end{array}$ & 102195 \\
\hline 159 & 42 & Rio Grande do Sul & Gravataí & $\begin{array}{l}\text { Hospital Dom João } \\
\text { Becker }\end{array}$ & 276525 \\
\hline 160 & 42 & Rio Grande do Sul & São Borja & Hospital Infantil & 68230 \\
\hline 161 & 42 & Rio Grande do Sul & São Leopoldo & Hospital Centenário & 215362 \\
\hline 162 & 42 & Rio Grande do Sul & Uruguaiana & $\begin{array}{l}\text { Hospital Geral Santa } \\
\text { Casa de Uruguaiana }\end{array}$ & 137789 \\
\hline 163 & 42 & Rio Grande do Sul & Venâncio Aires & $\begin{array}{l}\text { Hospital São } \\
\text { Sebastião Mártir }\end{array}$ & 68300 \\
\hline 164 & 42 & Santa Catarina & Blumenau & $\begin{array}{l}\text { Hospital Santo } \\
\text { Antonio }\end{array}$ & 304162 \\
\hline 165 & 42 & Santa Catarina & Icara & $\begin{array}{l}\text { Fundação Social } \\
\text { Hospitalar de Icara }\end{array}$ & 57599 \\
\hline 166 & 43 & Paraná & Curitiba & Hospital de Clínicas & 1818948 \\
\hline 167 & 43 & Paraná & Curitiba & $\begin{array}{l}\text { Centro Médico } \\
\text { Comunitário Bairro } \\
\text { Novo }\end{array}$ & 1818948 \\
\hline 168 & 43 & Paraná & Curitiba & $\begin{array}{l}\text { Hospital do } \\
\text { Trabalhador }\end{array}$ & 1818948 \\
\hline 169 & 43 & Paraná & Curitiba & $\begin{array}{l}\text { Hospital Universitário } \\
\text { Evangélico de } \\
\text { Curitiba }\end{array}$ & 1818948 \\
\hline 170 & 43 & Paraná & Curitiba & $\begin{array}{l}\text { Hospital e } \\
\text { Maternidade Victor } \\
\text { Ferreira do Amaral }\end{array}$ & 1818948 \\
\hline 171 & 43 & Paraná & Curitiba & $\begin{array}{l}\text { Clinica e Maternidade } \\
\text { Mater Dei }\end{array}$ & 1818948 \\
\hline 172 & 43 & Paraná & Londrina & $\begin{array}{l}\text { Hospital Universitário } \\
\text { Regional do Norte do } \\
\text { Paraná }\end{array}$ & 503041 \\
\hline 173 & 43 & Rio Grande do Sul & Caxias Do Sul & Hospital Geral & 419852 \\
\hline 174 & 43 & Rio Grande do Sul & Porto Alegre & $\begin{array}{l}\text { Hospital Materno } \\
\text { Infantil Presidente } \\
\text { Vargas }\end{array}$ & 1453076 \\
\hline 175 & 43 & Rio Grande do Sul & Porto Alegre & $\begin{array}{l}\text { Irmandade Santa } \\
\text { Casa de Misericórdia } \\
\text { de Porto Alegre }\end{array}$ & 1453076 \\
\hline 176 & 43 & Rio Grande do Sul & Porto Alegre & Hospital de Clinicas & 1453076 \\
\hline 177 & 43 & Rio Grande do Sul & Porto Alegre & Hospital Femina As & 1453076 \\
\hline 178 & 43 & Rio Grande do Sul & Porto Alegre & $\begin{array}{l}\text { Hospital Nossa } \\
\text { Senhora da } \\
\text { Conceição As }\end{array}$ & 1453076 \\
\hline 179 & 43 & Santa Catarina & Florianópolis & Hospital Universitário & 416269 \\
\hline 180 & 43 & Santa Catarina & Florianópolis & $\begin{array}{l}\text { Maternidade Carmela } \\
\text { Dutra }\end{array}$ & 416269 \\
\hline
\end{tabular}




\begin{tabular}{|c|c|c|c|c|c|}
\hline NN.. & Estrato & UF & Município & Instituição & Pop. 2007 \\
\hline 181 & 51 & Goiás & Ceres & Hospital São Pio X & 18894 \\
\hline 182 & 51 & Goiás & Posse & $\begin{array}{l}\text { Hospital Municipal Dr. } \\
\text { Arquimedes Vieira de } \\
\text { Brito Posse }\end{array}$ & 28273 \\
\hline 183 & 51 & Mato Grosso & Alta Floresta & $\begin{array}{l}\text { Hospital Municipal } \\
\text { Alta Floresta Albert } \\
\text { Sabin }\end{array}$ & 47326 \\
\hline 184 & 51 & Mato Grosso & Barra do Bugres & $\begin{array}{l}\text { Hospital Municipal de } \\
\text { Barra do Bugres }\end{array}$ & 33560 \\
\hline 185 & 51 & Mato Grosso & Peixoto de Azevedo & $\begin{array}{l}\text { Hospital Municipal de } \\
\text { Peixoto de Azevedo }\end{array}$ & 16744 \\
\hline 186 & 51 & Mato Grosso & Pontes e Lacerda & $\begin{array}{l}\text { Hospital Vale do } \\
\text { Guaporé }\end{array}$ & 43218 \\
\hline 187 & 51 & Mato Grosso do Sul & Aquidauana & $\begin{array}{l}\text { Hospital Joaquim } \\
\text { Correa de } \\
\text { Albuquerque }\end{array}$ & 46925 \\
\hline 188 & 51 & Mato Grosso do Sul & Nova Andradina & $\begin{array}{l}\text { Hospital das Clínicas } \\
\text { Santa Helena }\end{array}$ & 40088 \\
\hline 189 & 51 & Mato Grosso do Sul & Ponta Porã & $\begin{array}{l}\text { Hospital Regional Dr. } \\
\text { José de Simone } \\
\text { Netto }\end{array}$ & 25416 \\
\hline 190 & 52 & Goiás & Águas Lindas de Goiás & $\begin{array}{l}\text { Hospital Municipal de } \\
\text { Águas Lindas }\end{array}$ & 178461 \\
\hline 191 & 52 & Goiás & Anápolis & $\begin{array}{l}\text { Maternidade Dr. } \\
\text { Adalberto Pereira da } \\
\text { Silva Anápolis }\end{array}$ & 324157 \\
\hline 192 & 52 & Goiás & Anápolis & $\begin{array}{l}\text { Santa Casa de } \\
\text { Misericórdia de } \\
\text { Anápolis }\end{array}$ & 324157 \\
\hline 193 & 52 & Goiás & Formosa & Hospital São Camilo & 94400 \\
\hline 194 & 52 & Goiás & Jataí & $\begin{array}{l}\text { Centro Médico } \\
\text { Municipal Serafim de } \\
\text { Carvalho }\end{array}$ & 86352 \\
\hline 195 & 52 & Goiás & Luziânia & $\begin{array}{l}\text { Hospital Regional de } \\
\text { Luziânia }\end{array}$ & 194238 \\
\hline 196 & 52 & Goiás & Planaltina & $\begin{array}{l}\text { Hospital Municipal } \\
\text { Materno Infantil } \\
\text { Santa Rita de Cássia }\end{array}$ & 102231 \\
\hline 197 & 52 & Goiás & Rio Verde & $\begin{array}{l}\text { Maternidade Augusta } \\
\text { Bastos }\end{array}$ & 139200 \\
\hline 198 & 52 & Goiás & Trindade & $\begin{array}{l}\text { Hospital de } \\
\text { Urgências de } \\
\text { Trindade Walda } \\
\text { Ferreira dos Santos }\end{array}$ & 105599 \\
\hline 199 & 52 & Mato Grosso & Cáceres & Hospital São Luís & 91714 \\
\hline 200 & 52 & Mato Grosso & Sinop & $\begin{array}{l}\text { Hospital e } \\
\text { Maternidade dois } \\
\text { Pinheiros }\end{array}$ & 108210 \\
\hline 201 & 52 & Mato Grosso & Sorriso & $\begin{array}{l}\text { Hospital Regional de } \\
\text { Sorriso }\end{array}$ & 52881 \\
\hline 202 & 52 & Mato Grosso & Várzea Grande & $\begin{array}{l}\text { Hospital e } \\
\text { Maternidade Santa } \\
\text { Rita }\end{array}$ & 260693 \\
\hline 203 & 52 & Mato Grosso do Sul & Corumbá & $\begin{array}{l}\text { Santa Casa de } \\
\text { Corumbá }\end{array}$ & 101903 \\
\hline 204 & 52 & Mato Grosso do Sul & Dourados & $\begin{array}{l}\text { Hospital Evangélico } \\
\text { Dr. Sra. Goldsby King }\end{array}$ & 189589 \\
\hline
\end{tabular}




\begin{tabular}{|c|c|c|c|c|c|}
\hline NN.. & Estrato & UF & Município & Instituição & Pop. 2007 \\
\hline 205 & 53 & Distrito Federal & Brasília & $\begin{array}{l}\text { Hospital Universitário } \\
\text { de Brasília }\end{array}$ & 2434033 \\
\hline 206 & 53 & Distrito Federal & Brasília & HRAN & 2434033 \\
\hline 207 & 53 & Goiás & Aparecida de Goiânia & $\begin{array}{l}\text { Hospital e } \\
\text { Maternidade Marlene } \\
\text { Teixeira }\end{array}$ & 470733 \\
\hline 208 & 53 & Goiás & Aparecida de Goiânia & Hospital Garaveto & 470733 \\
\hline 209 & 53 & Goiás & Goiânia & $\begin{array}{l}\text { Maternidade Dona } \\
\text { Íris }\end{array}$ & 1239651 \\
\hline 210 & 53 & Goiás & Goiânia & $\begin{array}{l}\text { Maternidade Nascer } \\
\text { Cidadão }\end{array}$ & 1239651 \\
\hline 211 & 53 & Goiás & Goiânia & $\begin{array}{l}\text { Hospital e } \\
\text { Maternidade Vila } \\
\text { Nova Ltda. }\end{array}$ & 1239651 \\
\hline 212 & 53 & Goiás & Goiânia & $\begin{array}{l}\text { Hospital Materno } \\
\text { Infantil }\end{array}$ & 1239651 \\
\hline 213 & 53 & Mato Grosso & Cuiabá & $\begin{array}{l}\text { Hospital e } \\
\text { Maternidade Bom } \\
\text { Jesus }\end{array}$ & 551856 \\
\hline 214 & 53 & Mato Grosso & Cuiabá & $\begin{array}{l}\text { Hospital Geral } \\
\text { Universitário }\end{array}$ & 551856 \\
\hline 215 & 53 & Mato Grosso & Cuiabá & $\begin{array}{l}\text { Hospital Santa } \\
\text { Helena }\end{array}$ & 551856 \\
\hline 216 & 53 & Mato Grosso do Sul & Campo Grande & $\begin{array}{l}\text { Hospital da Mulher } \\
\text { Vó Honória Martins } \\
\text { Pereira }\end{array}$ & 780593 \\
\hline 217 & 53 & Mato Grosso do Sul & Campo Grande & $\begin{array}{l}\text { Hospital Regional de } \\
\text { Mato Grosso do Sul }\end{array}$ & 780593 \\
\hline 218 & 53 & Mato Grosso do Sul & Campo Grande & Santa Casa & 780593 \\
\hline 219 & 53 & Mato Grosso do Sul & Campo Grande & Aami & 780593 \\
\hline
\end{tabular}




\section{ANEXO C - QUESTIONÁRIO DE REGISTRO DE DADOS}

0624448749

\begin{tabular}{c} 
Projeto \\
Sentinela \\
Parturientes \\
\hline
\end{tabular}

\section{Questionário de Registro de Dados}

MÓDULO I - Identificação

ETIQUETA

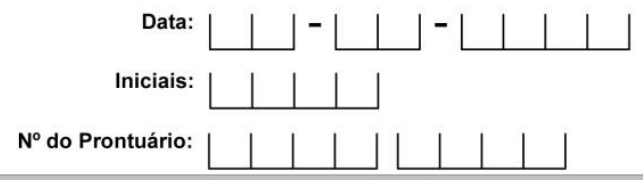

MÓDULO II - Dados sócio-demográficos (entrevista ou prontuário)

Q1. Data de nascimento:

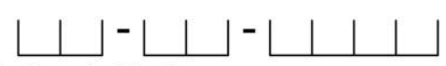

Q2. Escolaridade:
$\square$ 1. Analfabeto
$\square$ 6. Ensino médio incompleto
$\square 2.1^{\mathrm{a}}$ a $4^{\mathrm{a}}$ série incompleta do $\mathrm{EF}$
$\square$ 7. Ensino médio completo
$\square$ 3. $4^{\mathrm{a}}$ série completa do EF
$\square$ 8. Educação superior incompleta
$\square 4.5^{\mathrm{a}}$ a $8^{\mathrm{a}}$ série incompleta do $\mathrm{EF}$
$\square$ 9. Educação superior completa
$\square$ 5. Ensino fundamental completo
$\square$ 10. Ignorado

Q3. Raça/Cor (auto declaração):
$\square$ 1. Branca
$\square$ 3. Amarela
$\square$ 5. Indigena
$\square$ 2. Preta
$\square$ 4. Parda
$\square$ 6. Ignorado

Q4. Município de residência:

Q5. UF:

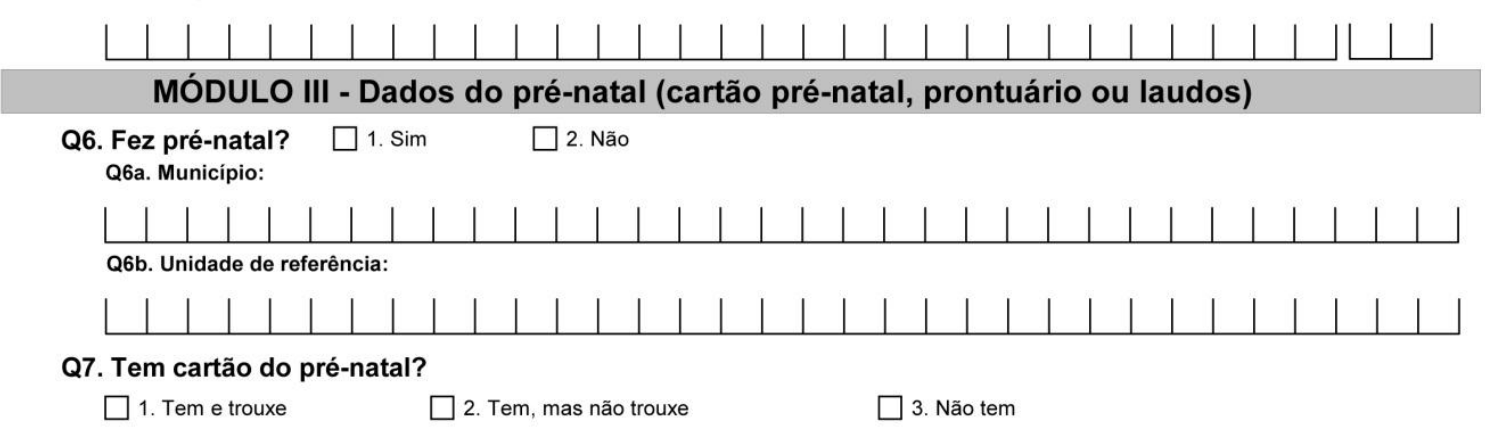

Q8. No de consultas de pré-natal:
$\bigsqcup$
$\square$ Não Preenchido

Q9. Data da primeira consulta:

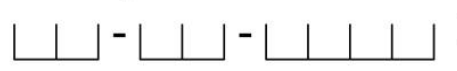

$\square$ Não Preenchido

Q10. Trimestre de início do pré-natal:
$\square 1.1^{\circ}$ trimestre (até 12 semanas)
$\square$ 3. $3^{\circ}$ trimestre (de 25 e mais semanas)
$\square$ 2. $2^{\circ}$ trimestre (de 13 a 24 semanas)
$\square$ 4. Não preenchido

Q11. Realizou Teste 1 de anti-HIV?
$\square$ 1. Sim
Q11a. Data
$\square$ 2. Não

Q12. Resultado do Teste 1 de anti-HIV:
$\square$ 1. Negativo
$\square$ 2. Positivo
$\square$ 3. Indeterminado 
4622448741

Q13. Realizou Teste 2 de anti-HIV?

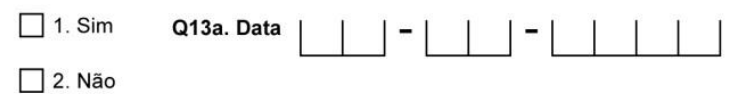

Q14. Resultado do Teste 2 de anti-HIV:
$\square$ 1. Negativo
$\square$ 2. Positivo
3. Indeterminado

Q15. Realizou Teste 1 de VDRL?
$\square$ 1. Sim
Q15a. Data
$\square$ 2. Não

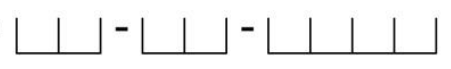

Q16. Resultado do Teste 1 de VDRL no pré-natal:
$\square$ 1. Negativo
$\square$ 2. Positivo
3. Não preenchido

Q16a. Titulo 1/ $|\quad| \quad \mid \quad$ Q16b. $\square$ 1. Título desconhecido

Q17. Realizou Teste 2 de VDRL?
$\square$ 1. Sim
Q17a. Data
$\square$ 2. Não

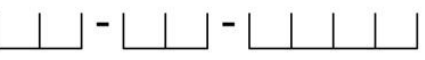

Q18. Resultado do Teste 2 de VDRL no cartão pré-natal:
$\square$ 1. Negativo
$\square$ 2. Positivo
$\square$ 3. Não preenchido
Q18a. Título 1/ $|\quad| \quad \mid$
Q18b. $\square$ 1. Título desconhecido

Q19. Coletou amostra para VDRL durante esta internação?

$\square$ 1. Sim

$\square$ 2. Não

Q20. Realizou teste para diagnóstico de hepatites?
$\square$ 1. Sim
$\square$ 2. Não
3. Não sabe
Q20a. O teste diagnóstico realizado foi para hepatite $\mathrm{B}$ ?
$\square$ 1. Sim
$\square$ 2. Não
$\square$ 3. Não sabe

Q21. Tem esquema completo (três doses da vacina) contra hepatite B?
$\square$ 1. Sim
$\square$ 2. Não
$\square$ 3. Não sabe

\section{MÓDULO IV - Resultado do Estudo}

Q22. Resultado do Teste rápido de HIV:
$\square$ 1. Negativo
$\square$ 2. Positivo
$\square$ 3. Inválido

Q23. Resultado do Teste rápido de Sífilis:
$\square$ 1. Negativo
$\square$ 2. Positivo
$\square$ 3. Inválido

MÓDULO V - Informações sobre o parto (prontuário ou cartão pré-natal)

Q24. Data do parto:

Q25. Situação do recém-nascido
$\square$ 1. Vivo
$\square$ 2. Natimorto

Q26. $N^{\circ}$ da declaracão de nascidos vivos - DN:

Q27. Responsável pelo preenchimento: 


\title{
ANEXO D - PARECER DO COMITÊ DE ÉTICA EM PESQUISA
}

\author{
MINISTÉRIO DA SAÚDE \\ Conselho Nacional de Saúde \\ Comissāo Nacional de Ética em Pesquisa - CONEP
}

PARECER $n^{\circ} 709 / 2009$

Registro CONEP 15409 [Este $n^{\circ}$ deve ser citado nas correspondéncias referentes a este projeto\}

Procosso $n^{\circ} 25.000 .506$ 165/2009-68

Projeto de Pesquisa: "Projeto de venificaçăo de prevaléncia do HiV, sifilis e hepatites $\mathrm{B}$ e C em parturientes - Brasil, 2009".

Pesquisador Responsável: Gerson Femando Mendes Pereira e Lilian do Amaral inocêncio

instituição: Ministério da Saúde (MS) - Secretaria de Vigilância em Saúde (SVS) Programa Nacional de DST e Aids

CEP de origem: Comissāo Nacional de Ética em Pesquisa

Área Temática Especial: Projeto multicêntrico

Patrocinador: Programa Nacional de DST e Aids (SVS-MS)

\section{Sumário geral do protocolo}

Trata-se de um estudo de caráter epidemiológico que será realizado pelo Programa Nacional de DST e Aids (SVS-MS) em 225 maternidades de todo o Brasil.

$O$ estudo pretende conhecer a prevalência da infecçăo pelo HIV sifilis $\epsilon$ hepatíes $\mathrm{B}$ e $\mathrm{C}$ a partir da detecçăo de anticorpos marcadores dessas infecções em amostras de sangue coletadas em parturientes ce modo identificado e vinculado com bese amostral Além dos dedos sorológicos, seräo realizadas entrevistas para preenchimento de questionário pré-estabelecido e coleta de dados do cartác de prénatal, Destacam-se assim, os objetivos especificos do estudo: a) obter estimativas nacionais e regionais da prevaléncia de HIV, sífilis e hepatites $\mathrm{B}$ e $\mathrm{C}$ em parturientes: b) comparar as estimativas de prevalência de HIV e sifilis geradas pelos dados primários (coleta) com as geradas pelos dados secundários (cartão pré-natal) das parturientes amostradas para o estudo; e c) avaliar a qualidade da assistência prénatal e assistência ao parto.

A vigilância sentinela é o método de escolha para que se obtenham dados de determinados agravos, a partir dos quais se pode monitorar o seu comportamento em orupos especificos.

O tamanho de amostra foi determinado para obter a estimativa da taxa de prevalência do HIV em gestantes para o Brasil e as grandes regióes.

Levando-se em consideraçăo a estimativa da proporçăo de gestantes infectadas pelo HIV em 2006, de 0,42\%, o tamanho da amostra necessário para estimar a proporção de infecçáo pelo HIV, dentro de um intervalo de confiança de $95 \% \mathrm{com}$ erro bilateral de $0,15 \%$ e efeito de desenho de 1,1 , foi estabelecido em 7855 parturientes, sendo aproximado para $8000 \mathrm{em}$ cada regiăo do pais, seiecionadas probabilisticamente

Esta amostra também permitirá a estimativa da taxa de prevalência da siffis e das hepatites $B \in C$, levando-se em consideraçăo que em estudos anteriores a estimativa da proporção dessas infecçb̄es é respectivamente de $1,6 \%, 1.43 \% \in$ $0.89 \%$, todas maiores que a prevalêncla do HV, mostrando que a amostra para 
Cont. Psrocer CONEP no $709 / 09$

determinar a prevalência do HIV é suficiente para determinar a prevalência desses agravos.

No estudo serฐ̃o incluidas as parturientes com idade entre 15 e 49 anos e que consentirem em participar como voluntárias do estudo, mediante assinatura do TCLE. Serão excluidas as pacientes internadas para curetagem pós-abortamento.

Os dados gerados serăo utilizados para o planejamento das açöes de prevençāo 8 controle dessas infecçōes, bem como melhoria da qualidade da assistência pré-natal.

\section{Loca! de realização}

Ao todo participarāo maternidades do SUS e maternidades conveniadas de 219 cidades de todas as regiöes do Brasit. Participarăo dos estudos as Unidades de Informaçāo e Vigilância e de Laboratório do Programe Nacional de DST/AIDS (CONEP) e o Laboratório de Pesquisa em HIVIAIDS da Universidade de Caxias do SUURS (CEP - Universidade de Caxias do Sul).

Apresentação do protocolo

Cs curriculos dos pesquisadores foram encarninhados e estäo adequados ao propósito da pesquisa. O orçamento financeiro apresentado é compativel com as atividades a serem desenvolvidas.

- projeto é exclusivamente nacional e a Comissäo Nacional de Ética en Pesquisa fará a análise e o acompanhamento do mesmo.

O instrumento que será utilizacio na coleta de dados (cartăo pré-natai, prontuário e entrevista) encontra-se no protocolo.

Consideracoues sobre a análise das respostas ao Parecer CONEP N ${ }^{\circ} 474 / 2009$, relativo ao projeto de pesquise em questão:

1. Com relacäo à Folha de Rosto, solicitamos que apenas um dos pesquisadores figure na Folha de Rosto como pesquisador responsável, para que se evitem problemas no cadastramento de documentos relativos ac protocolo e oara facilitar as rotinas de correspondência, contato com os pesquisadores e emissăo de documentos. Solicita-se adequaçăo.

Resposta: De acordo ao solicitado, passa a constar apenas um pesquisador como responsável pelo projeto.

Análise: Pendēncia atendida.

2. Ainda sobre a Folha de Rosto, é necessário que seja assinalado, no campo "Grupos especiais", o item "<18 anos", além de manter o item "Outros" assinalado. Solicita-se adequacăo

Resposta: De acordo ao solicitado, passa a constar no campo "Grupos Especiais" o item "18 anos" e fol mantido o item "Outros".

Análise: Pendéncia atendida.

3. Centros no Brasil: a lista deverá conter o nome da instituiçăo, o estado ac qual pertence (UF), o Comite de Ética em Pesquisa - CEP responsavel por acomoanhar a pesquisa e o nome do pesouisador em cada centro. No protocolo em cuestão, aparentemente, o único centro que fará parte da pesquisa será Laboratório de Pesquisa em HIVIAIDS da Universidade de Caxias do SUl/RS (LPHAUUCS). Indicamos o Comitê de Ėtica em Pesquisa da Universidade de Caxias do Sul para acompanhar o desenvolvimento do estudo. Contudo, ainda é necessário que se informe quem será o pesquisador responsável pelo estudo no refericio centro. Solicita-se adequaçāo. 
Resposta: Houve um engano no preenchimento da folha de rosto. O projeto em questāo nâo configura como estudo multicêntrico. O projeto é coordenado pelo Ministério da Saúde através do Departamento de DST $\in$ AIDS. No entanto, fo: incluido na lista de amostragem (Tabela I) o nome das maternidades participantes

Análise: Pendência atendida.

4. Declaração dos critérios para suspender ou encerrar a pesquisa e Declaraçāo sobre uso e destino dos materiais elou dados coletados na pesquisa

Resposta: Os dados coletados na pesquisa serão utilizados conforme descrito no item If (objetivos) que sâo: a) Obter estimativas nacionais e regionais da prevalência de HV $\in$ sifilis em parturientes; b) Obter estimativa nacional da incidência de HV em parturientes: c) identificaçăo da resistência da incidéncia de HIV aos Antiretrovirais; d) Comparar as estimativas de prevalência de HIV sifilis geradas pelos dados primérios (coleta) com as geradas pelos dados secundários (prontuário e cartăo pré-natal) das parturientes amostradas para o estudo; e) Avaliar a qualidade da assistência pré-natal e assistência ao parto. A pescuisa dar-se-á por encerrada quando for atingido o "N" amostral $(43.800)$, permitido alçarem-se os objetivos precitados e devidamente divulgado.

Análise: Pencéncia atendida.

5. O cronograma precisa ser atualizado, pois a análise do protocolo pela CONEP foi prevista para abril. Solicita-se adequaçăo.

Resposta: De acordo ao solicitado, o Cronograma foi atualizado considerando o inicio do Projeto para o mês de setembro.

Análise: Pendência atendida.

6. Sobre o Termo de Consentimento Livre e Esclarecido (TCLE):

a. Adequação do TCLE à realidade das voluntárias menores de 18 anos, cuja participação deverá, inclusive, contar com a anuência dos pais cu responsáveis.

Resposta: De acordo ao solicitado, passa a constar a anuência do responsável legal.

Análise: Pende̊ncia atendida.

b. Descriçāo apropriada dos objetivos e da justificativa: o TCLE è muito sucinto sobre esses tópicos. Seria importante informar que se trata de uma pesquisa de âmbito nacional, envolvendo mulheres de todo o pais. E que as informaçōes obtidas serāo de grande importância para a orientaçäo das açōes de saúde publica, principaimente na elaboraçắ de açōes de prevenção. Enfim, é necessário que os pesquisadores acrescentem algumas infomaçōes ao TCLE, de modo que as voluntárias possam ter uma compreensảo mais adequada da pesquisa e de suas finalidades.

Resposta: De acordo ao solicitado, complementaram-se os objetivos e es justificativas.

Análise: Pendência atendida,

c. Indicaçăo de forma de acompanhamento e assistência médica: é necessário acrescentar ao TCLE as informaçōes que os pesquisadores apresentaram no projeto, afirmando que. diante de um diagnóstico positivo para algumas das infecçōes, as voluntárias e seus filnos serác encaminhados para acompanhamento específico.

Resposta: De acordo ao solicitado, incluiu-se a questâo de assisténcia e o ecompenhamento as parturientes e recèm-nascido cujo resuitado sejam positivos. 
Análise: Pendência atendida.

d. Indicaçăo das formas de indenizaçāo diante de eventuais danos decorrentes da pesquisa (reparaçăo do dano): é necessário informar à voluntária que diante da ocorrência de qualquer dano que apresente relaçäo causal comprovada com o desenwolvimento do estudo, a mesma terá direito à indenizaçẫo e que a assinatura do TCLE não representa uma obstruçāo ao exercicio deste direito.

Resposta: Embora todos os procedimentos a serem executados façam parte da rotina de atendimento ao parto, incluiu-se que a parturiente e o recém-nascido receberăo assistência a saúde por qualquer dano causado comprovadamente pelo estudo.

Anàlise: Pendência atendicia.

Diante do exposto, a Comissão Nacional de Ética em Pesquisa - CONEP, de acorcio com as atribuiçōes definidas na Res. CNS 196/96, manifesta-se pela aprovação do projeto de pesquisa proposto.

Situaçăo: Protocolo aprovacio.

Brasilia, 08 de outubro de 2009

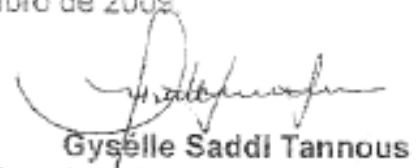

Coordenedora da CONEPICNSMS 